\title{
UN PATIO QUICHUA CON FRECUENCIA MODULADA
}

\author{
Héctor ANDREANI ${ }^{1}$
}

\section{Resumen}

Analizamos los usos del bilingüismo (quichua-castellano), explorando la trama de participantes "quichuistas" de un programa radial desarrollado desde 2008 en un pueblo mesopotámico santiagueño (Argentina). Dada su "efectividad social", y por fuera de explicaciones posmodernas o chauvinistas, describimos cómo el proceso radial es un propagador del repertorio bilingüe generado en el trabajo migrante estacional. Esta investigación etnográfica sobre el despliegue de esa fuerza motriz ofrece una explicación material más efectiva sobre las causas del mantenimiento lingüístico.

Palabras clave: Repertorio bilingüe quichua/castellano - Programa radial - Ideologías lingüísticas - Fuerza motriz - Picardía agonística

\begin{abstract}
We analize the uses of bilingualism (Quichua-Spanish), exploring the network of "Quichuist" participants in a radio program developed since 2008 in a Mesopotamian town from Santiago del Estero (Argentina). Given its "social effectiveness", and outside of postmodern or chauvinist explanations, we describe how the radio process is a propagator of the bilingual repertoire generated in seasonal migrant labor. This ethnographic investigation of the deployment of this driving force offers a more effective material explanation of the causes of linguistic maintenance.
\end{abstract}

Key words: Bilingual Quichua/Spanish repertoire - Radio program - Linguistic ideologies - Driving force - Agonistic mischief

\footnotetext{
${ }^{1}$ Universidad Nacional de Santiago del Estero sachahector@gmail.com
}

Fecha de recepción del artículo: Marzo2021

Fecha de evaluación:Abril 2021 


\section{Résumé}

Nous analysons les usages du bilinguisme (quichua-espagnol), explorant le réseau des participants «quichuistes» à une émission radiophonique développée depuis 2008 dans une ville mésopotamienne de Santiago (Argentine). Compte tenu de son «efficacité sociale», et en dehors des explications postmodernes ou chauvines, nous décrivons comment le processus radio est un propagateur du répertoire bilingue généré par la main-d'œuvre migrante saisonnière. Cette enquête ethnographique sur le déploiement de cette force motrice offre une explication matérielle plus efficace des causes du maintien linguistique.

Mots clés: Répertoire bilingue quichua-espagnol - Programme radio - Idéologies linguistiques - Force motrice - Méfait agonistique

1. Bibliografía

\section{Introducción}

En este artículo abordamos la trama interna de un programa radial emitido en registro bilingüe (quichua-castellano), desarrollada con discontinuidades desde 2008 hasta la fecha, en un pueblo del sur mesopotámico de Santiago del Estero (SdE), Argentina. Nos preguntamos bajo qué formas y caminos una lengua minorizada llega a abrir horizontes discursivos en ámbitos no usuales; qué estrategias logran desplegar sus participantes, tanto en cierta eficacia social como en sus limitaciones intrínsecas; y qué fuerza social es la que motiva el orden de estos usos lingüísticos. Tomamos este caso "intenso" porque refracta notablemente lo que ocurre a nivel sociolingüístico en el espacio mesopotámico sur, cuyos parámetros pueden ser verificables a las restantes zonas de habla quichua en SdE. No nos detenemos en los datos del trabajo de campo etnográfico sino que buscamos comprender a) el grado de "eficacia" social de un producto medial cuyo foco es la lengua misma y b) cuál es la fuerza motriz que sostiene sociolingüísticamente estas prácticas y discursos desplegados.

Dejamos de lado los abordajes sobre el quichua referidos a períodos prehispánico, colonial y decimonónico (entre muchos otros, Bravo 1956; Stark 1985; Landsman 2000; Alderetes 2001; Karlovich 2006; Grosso 2008; Togo et al. 2008; Chang 2020;). Más ubicados sobre el período contemporáneo, las perspectivas críticas del desplazamiento se enfocaron efectivamente en causas migracionales al modo de "éxodos" (Alderetes 2001; Albarracín y Alderetes 2004) y la eficacia del discurso sarmientino totalizante en las escuelas (Landsman 2000; Karlovich 2006, Grosso 2008). Estas posiciones críticas, mediante muchas publicaciones en dos décadas, han alertado y denunciado el cuadro negativo que atraviesa el quichua. Sin embargo, en los antecedentes no hay un desarrollo explícito sobre las condiciones de mantenimiento, con lo cual reconstruimos argumentos. Ciertas posiciones críticas postulan que consecuentemente al despojo económico (Alderetes 2001), se habrían generado ciertas actitudes de "resistencia" producto de la "identidad" lingüística de sus hablantes (Albarracín y Alderetes 2001; Albarracín 2009; 2015). Por otro lado, posiciones más posmodernas explican el mantenimiento desde un comportamiento social no deliberado que practicarían 
cotidianamente los bilingües, en donde el quichua sería un conjunto de prácticas residuales denominadas semiopraxis (Grosso 2008; 2019). En el fondo, esta fenomenología reactualiza el primordialismo culturalista, donde "lo indio" sería un flujo residual y vigente que "fluye" por debajo del discurso de la "modernidad".

Nuestra problematización enfoca en que la escasa literatura referida a esta variedad quechua, si bien con datos valiosos, no propone una mirada de conjunto para comprender cuáles fueron, o siguen siendo, las condiciones efectivas para el mantenimiento lingüístico, sea el que fuere y por fuera de proyecciones ingenuas sobre revitalización. Estas miradas sobre el mantenimiento actual se basan principalmente en a) en atributos identitarios o culturalistas; b) el accionar direccional de sectores dominantes que hablarían castellano hacia sectores completamente pasivos que hablarían quichua; c) la reacción bajo la forma de "resistencia" lingüística, como si hubiera una deliberada política de visibilización endógena sobre dicha lengua; d) prácticas "subrepticias", "subalternas", subterráneas por debajo de las prácticas "dominantes". Sin base en evidencia empírica, se interpreta que hay un desplazamiento absoluto y unidireccional hacia una población vista con diferentes grados de pasividad ${ }^{2}$. Subyace el concepto de bilingüismo como si fuera la sumatoria de monolingüismos (cf. Lüdi y Py 2009), subsidiaria de la idea de lengua atravesada por la formación histórica de los Estados-Nación (Nussbaum 2012). No se estudia el proceso social para entender por qué no desapareció el quichua, y tampoco los procesos de socialización lingüística (Schieffelin y Ochs 1986; Unamuno 2011; Andreani 2020) que superan la mirada de que las lenguas se transmiten de modo direccional, o de que solo la transmisión familiar sería el mecanismo excluyente de socialización (cf. Unamuno 2013). Hay, entonces, una complejidad en las relaciones sociales reales por abordar (Flores 2012), bajo las cuales se desarrollan los efectivos procesos sociolingüísticos endógenos (cf. Wittig 2009) que afectan a este sector poblacional.

Para este estudio de caso, nos sostenemos en perspectivas de la sociolingüística etnográfica, que vienen abordando aquello que los hablantes hacen con las lenguas, y no en miradas sociolingüísticas predominantes que interpretan un proceso a partir de la intuición o autopercepción de los hablantes. Gumperz y Hymes (1972) postularon el clásico concepto de repertorio como el conjunto de recursos a disposición de las personas para actuar socialmente, problematizando notoriamente la idea de lengua como una entidad monolítica. Lo desplegado siempre es un repertorio porque incluye variedades linguiísticas, géneros discursivos, actos de habla y hasta marcos interpretativos propios de este grupo de participantes radiales (pero veremos que no solo ellos). Lo interesante es que esos repertorios se componen no solo de formas lingüísticas y configuraciones semánticas y pragmáticas para producir e interpretar significados situados, sino que también incluye formas de "expresión multimodales

\footnotetext{
${ }^{2}$ En la interpretación sociolingüística de Alderetes (2001) el desplazamiento del quichua se explica por la pasividad poblacional junto con el extractivismo forestal; esto es subsidiario del revisionismo histórico nacionalista sobre el "despojo a manos del "imperialismo" (Di Lullo 1937; Scalabrini Ortiz 1940; Alén Lascano 1992; Dargoltz 2003). Pero otros aportes historiográficos evidencian procesos productivos no restringidos a la destrucción forestal del Chaco santiagueño (Tasso 2007) o procesos decimonónicos no reductibles a la mera dominación política unidireccional (Carrizo 2014) o con formaciones comunales diferenciadas (Farberman 2019).
} 
incardinadas en el discurso" y culturalmente reconocibles en la comunidad (Mondada, 2004). Sobre esto, veremos cómo despliegan recursos socialmente valorados como la picardía, el agonismo, el machismo, el purismo lingüístico, entre otros. Actuar en contextos bi/multilingües supone que el hablante debería desplegar capacidades para emplear, interpretar y dar sentido al uso de todo tipo de recursos (Nussbaum, 2012: 274). Por ejemplo, ante cada emisión del programa radial, surgía la necesidad de sus participantes de "afilar los cuchillos" cuando les tocara hablar por micrófono. Es decir, ellos debían preparar previamente su speech, o su repertorio quichua deliberado. Nos interesa la idea de que los recursos lingüísticos constantemente se están reorganizando, por su puesta desplegada en el juego de la interacción (Mondada, 2004). Aclaramos que no desarrollamos herramientas teóricas sobre el ámbito radial en sí mismo (ej. Muñoz 1997; Cebrián Herreros 2001; Dávila y Finol 2003), sino que nos centraremos en el desarrollo del proceso sociolingüístico habilitado por el programa radial.

Observamos que el orden de usos bilingües, las ideologías lingüísticas manifiestas, el repertorio desplegado (y también percibido como tal) y las acciones realizadas por sus participantes, dan cuenta de un ámbito bilingüe que oscila entre el subjetivismo y ciertas condiciones de habilitación para un precario objetivismo lingüístico (Voloshinov 1992). Ciertas expresiones de ideologías subjetivistas sobre el lenguaje, como la picardía, el agonismo, el machismo y el purismo lingüístico, son intensas por su particular valoración en ese juego social. Tomamos el concepto de fuerza motriz que proviene de varias ramas divergentes de la sociolingüística y la linguiística histórica (Labov 2002; Brighton 2003; Heggarty y Beresford-Jones 2010) pero lo redefinimos como la capacidad social de poner en movimiento un repertorio (recursos lingüísticosideológicos-discursivos-comunicativos) para expandir o mantener una lengua dentro de una configuración sociohistórica determinada. Cada fuerza motriz responde a condiciones materiales y a determinada configuración de las relaciones sociales. Seguiremos el trayecto de un bilingüe que inicia su gestión cultural como locutor, para pasar a una trama social más compleja con el programa radial, hasta dar con la naturaleza de clase de todos los participantes. Observaremos cómo se desarrolla un proceso bilingüe, cuya motivación ideológica en realidad no surge del programa radial mismo, sino que este sirve como potenciador-propagador de ámbitos externos denominados como "trabajo golondrina" (migrante estacional agrario). Dicho de otro modo, exploraremos cómo determinadas relaciones sociales de explotación reconfiguran -por vías que deben ser reconstruidas- a prácticas culturales muy específicas (como un programa radial) que habilitan el mantenimiento (si bien inestable) de una lengua muy minorizada y una zona periférica de Argentina. Y esto solo puede ser analizado desde una perspectiva etnográfica sobre un espacio social específico, donde los pobladores despliegan sus repertorios bilingües.

Precisamos, entonces, una perspectiva que contemple la totalidad, esto es, las relaciones sociales efectivas, y a la vez basado en evidencia empírica desde las interacciones de la comunidad lingüística a explorar (Hymes 1972; Duranti 2000). Una descripción de la política vivida (Quirós 2014) en un ámbito rural, junto con dinámicas de clase en un espacio específico (Flores 2018) y el registro de interacciones bilingües en un terreno real (Tusón Valls 2002; Unamuno 2012; Gandulfo 2007) nos permiten ofrecer una explicación diferente al mantenimiento de una lengua minorizada, lejos de postulación 
de la supuesta "resistencia" de sus hablantes, de las explicaciones chauvinistas (discursos exacerbados de la provincianía) o de cierta fenomenología difusa basada en primordialismos culturalistas ("semiopraxis").

\section{Involucrarse}

Tincho siempre fue inquieto. En los 90, mientras cursaba en el colegio de Llaqta Sur ${ }^{3}$, una profesora lo acercó a Neruda y Almafuerte, en libritos que componían esa escasa biblioteca del colegio, polvorienta, muy poco frecuentada por los docentes, mucho menos los chicos. Aunque jamás llegó a tener una ortografía correcta, y aunque Tincho jamás lo reconociera (jamás le daría ese lugar en su vida y en su memoria), es indudable que la escritura muchísimas veces fue un verdadero pasatiempo para él. Nunca dejó de jugar a que hacía poesía, con hojas sueltas y rayones en las carpetas del colegio. Aunque nunca se dedicó del todo, en él siempre hubo algo que lo acercaba a la escritura. Se enteraba de presentaciones de libros en Capital o recortaba poemas que aparecían en los diarios viejos que iban llegando a su rancho, y también por los programas de frecuencia provincial que escuchaba en la radio chiquita a pilas, colgada en uno de los horcones. A pesar de los smartphones que tantos muchachos fueron adquiriendo con el dinero del trabajo golondrina (migrante rural estacional) desde 2013 o 2014 en adelante, la radio pequeña sigue siendo útil e inseparable en miles de familias obreras rurales de Santiago del Estero.

Siendo adolescente, Tincho esperaba ansiosamente los encuentros de lengua quichua que se organizaban en la escuela primaria de Llaqta. Desde mediados de los 90, este encuentro congregaba a docentes rurales, investigadores exógenos de esta lengua (los únicos, además de escasos), escritores amateurs de ciudades cercanas con sus libritos de escasa proyección, y sobre todo muchos folkloristas. Sin embargo, del pueblo y de los alrededores asistía muy poca gente. A veces nadie. También se acercaban "notables" amateurs de la ciudad que se apostaban en alguna "mesa panel", para declamar románticamente sobre la "defensa de nuestra lengua ancestral", aunque sin espectadores que les prestaran mucha atención, o que se iban retirando en silencio. Tincho se deleitaba con estos encuentros en la escuela, en medio del viento helado de junio (compitiendo con el insufrible sol de enero). En esos encuentros Tincho-siempre inquieto- terminaba "ligando" algún libro de quichua, o algún diccionario, entre otros libros que fue recibiendo o comprando con dinero forzoso cada vez que lograba viajar a Santiago Capital. Guardados en la siempre improvisada "bibliotequita" del aparador de su casa, sus "libros de quichua" descansaban junto con colecciones de Visor, enciclopedias compradas a algún vendedor, varios poemarios de Neruda, y varias biografías del Che y de Evita adquiridas en kioscos.

Cuando era niño, junto con sus hermanos, Tincho acompañaba a su padre en el camión viejo de riego (Dependencia Provincial) para dar agua a las familias más aisladas o

\footnotetext{
${ }^{3}$ Todos los nombres propios y geográficos son ficticios. Utilizo un estilo de escritura, no en el sentido de descripción densa (a lo Geertz) sino más bien como descripción lenta, en los términos que propone Quirós (2011). Hay un proceso social con fuertes implicancias en las acciones de Tincho, Pedro, Shisha y los demás participantes, con lo cual deja de ser una aplicación de individualismo metodológico. Por ende, se convierte en un caso intenso con proyección extendida en una zona muy amplia (siempre en el interés sobre los usos de esta lengua).
} 
distantes del pueblo. Así, los changos aprovechaban esos viajes "de aventura" para conocer los numerosos parajes que desesperaban por agua potable, o al menos agua menos salada de la que salía en los pozos. Con tal de conocer los caminos (para alardear después en la escuela ese conocimiento) ellos eran capaces de aguantar las altísimas temperaturas dentro de la cabina, viajando todo el día, y a veces volvían al pueblo con la noche encima. El agua directamente salvaba la vida de esa gente. Con el tiempo, esos caminos recorridos devinieron tema de discusión temprana de Tincho en el colegio: ya no era un mero "conocimiento" local frente a los demás, sino como sensación de indignación acumulada. Eran demasiadas las familias con ojos llorosos cuando veían venir el camión lleno de agua. Los hermanitos en esa cabina caliente del camión, mirando la desolación en ese apretar de manos de la gente como agradecimiento a su papá, don Nacho, un obrero estatal que pasó 35 años de su vida arriba de camiones.

Ninguno de ellos tiene problemas para contarme cómo eran, entre los años 80 y 90, esas innumerables visitas a las familias. Según ellos, interactuaban en todo momento en quichua, calmando primero a la abuela o a la madre con bebés en brazos, y después charlando sobre lo sufridos que estaban, y después discutiendo con don Nacho porque él no aceptaba la tortilla como agradecimiento. Mucho menos algún cabrito sacrificado para la ansiada llegada del agua. El agradecimiento material de gente "que no tiene nada de nada" es muy fuerte en la memoria de Tincho, sus dos hermanos y don Nacho. Es fácil imaginar cómo esas "necesidades" fueron el germen del posicionamiento político de Tincho años después, cuando fue impostergable la necesidad de "meterse en política".

Hubo mucha literatura local en el siglo XX sobre ciclos indomables de sequías e inundaciones ${ }^{4}$, que postergaron indefinidamente a estas poblaciones laboriosas y al ganado sufrido, siempre en un terreno de llanura extensiva y de bosques xerófilos. Las memorias históricas de inundaciones y sequías prolongadas proviene del siglo XIX $(1811,1822,1847)$, con más fuerza en el siglo XX (década del 20, la gran sequía de 1937-41, inundación del 58, sequía de mediados del 60, inundación del 74-75, inundación de mediados del 80, sequía extrema de 2005-2008, ola de calor histórica entre 2013-2014) dan cuenta de que los obstáculos climáticos fueron importantes para que no se desarrollara sostenidamente una estructura agroganadera a gran escala en gran parte de la provincia, sino más bien con muchas discontinuidades (cf. Tasso 2007).

Hoy las condiciones estructurales no han cambiado: solamente en algunas casas pudieron adquirir un aljibe de "cal y canto", o por alguna acción asistencial del municipio para casos realmente extremos. En amplios sectores de toda la franja sur de $\mathrm{SdE}$, varias familias recuerdan que a mediados de los 80 fue la última vez que sembraron algo para subsistir con lo mínimo. Posteriormente, la práctica de sembrar desapareció sin transmitirse a sus hijos y nietos. De ahí la profundización de los ciclos migratorios a Buenos Aires y las cosechas de la Pampa Húmeda. Desde los 13 años, Tincho y otros chicos comenzaron a viajar con sus parientes para aprender el duro oficio de la "desflorada" de maíz.

En 2007 y con 23 años, Tincho mismo no recordaba demasiado sobre temas de siembra. Por el escaso cuidado que precisa, poseen solo pequeñas tropillas de cabritas o gallinas,

\footnotetext{
${ }^{4}$ Entre muchos otros, Carol (1943), Quenel (1951), Tasso (2011).
} 
y alguna familia puede llegar a tener escasas vacas. Su padre mismo tiene un caballo que intentó criar para carreras de cuadreras; lo habían bautizado "Huaira Muyoj" 5 porque supuestamente era veloz. No los motivaba alguna dinámica del tipo "campesino" (en el sentido de autonomía, autosubsistencia, paraíso idílico o identidad política actual) sino que ese caballo era a la vez una inversión riesgosa y un potencial ingreso de dinero por las apuestas de carrera. En síntesis, se trata de obreros rurales en tierras que funcionan como espacios muy limitados para su reproducción de vida (Desalvo, 2013; Muñoz, 2018) y buscan otras estrategias más sostenidas de ingreso extrapredial. Un elemento fundamental aunque soslayado por la sociolingüística, es precisamente el trabajo migrante estacional, cuyos flujos migratorios provienen del siglo XVIII (Farberman, 1992) y que se intensificó notablemente en todo el siglo XX hasta la actualidad. Adelantamos que este último punto es determinante para las conclusiones de esta investigación: planteamos polémicamente que si buscamos caracterizar socialmente los usos sociales del quichua, estas condiciones materiales son las que debemos contemplar y no los discursos identitarios surgidos de los hablantes.

Tincho, como sus vecinos, está plagado de memorias sobre estas sequías e inundaciones ${ }^{6}$. Uno de los temas predilectos en muchas charlas y discusiones familiares donde estuve entre 2008-2015 (sentados en su patio de cemento, tomando unos mates insoportablemente azucarados) era criticar al comisionado municipal que estaba en 2010, por la distribución del agua. Los reclamos de los puebleros era que el agua distribuida no debía cobrarse y tenía que ser gratuita:

Pablito (hermano de Tincho)- ¿Cómo le van a querer estar cobrando por el agua a esas pobres gentes que saben estar bullando con tierra en la garganta?

Don Nacho- Yo solo llevo el agua, yo no decido que haya que cobrarles, me mato haciendo andar a ese camión, yo veo cómo le andan sufriendo las gentes de monte adentro -me decía ofuscado don Nacho- pero me ordenan que les cobre y les tengo que cobrar, yo les tengo que decir que eso no es plata para mí, que la comisión me quiere hacer que les cobre. Encima te quieren regalar un cabrito igual, a pesar de que les tengo que cobrar. No tienen nada esas gentes y encima te quieren hacer que les recibas un cabrito.

Un sobrino acordaba con don Nacho en que las cosas nunca iban a cambiar. "Pero es un servicio público eso, hay que cambiar. Si le prometemos a la gente que vamos a luchar

\footnotetext{
${ }^{5}$ Wayra Muyoq (remolino, viento que gira, en quichua).

${ }^{6}$ En una de tantas visitas a Tincho y a sus conocidos, en 2009 sucedió una desgracia. Un caballo llegó al galope, sin dueño desde "monte adentro", enloquecido de sed al pueblo. De algún modo, olía a la distancia la escasa agua que quedaba en un aljibe de la calle de Tincho. Bastó que llegara a un aljibe muy profundo. Aun con un pequeño manto de agua musgosa de cinco centímetros, se arrojó con desesperación. Me bajé del colectivo y me acerqué: varios vecinos intentaban sacar ese cuerpo musculoso que solo hacía horrorosos espasmos. El pobre caballo, agonizante por el golpe inmediato de 12 metros contra el piso de cemento. Dante, un vecino que es maestro, le dio un disparo certero con su escopeta para que dejara de sufrir. En la sequía de 2005, había cientos y cientos de animales yaciendo muertos, al costado de los caminos y las rutas asfaltadas, secos y con panzas hinchadas de agua, en medio de un pequeño abrevadero que los confunde con la trampa del barro. Todos en el barrio estaban muy compungidos después de ese disparo.
} 
para que el agua sea gratis... ¡chango! Nos vamos a llenar de votos así”, retrucaba Tincho. Estábamos a un año de las elecciones.

Desde hace treinta años, el mismo comisionado era Segovia. Posterior a la crisis política, la intervención federal y el rearmado total del tablero político con un nuevo gobierno provincial en 2005 (absolutamente alineado al gobierno bonapartista de Néstor Kirchner hasta la fecha), las comisiones municipales ya no serían puestas a dedo como fue ininterrumpidamente durante todo el siglo XX. Ahora se instauraban elecciones ordinarias en cada comisión rural. El aparato electoral estaba asegurado para el gobierno provincial, puesto que en pocos años los candidatos de todas las comisiones se disputaban la elección a nombre del mismo gobierno provincial, casi sin candidatos opositores. Desde esos años, los conflictos políticos "locales" se intensificaron notablemente en todo el espacio rural provincial.

En Llaqta Sur nadie se había presentado para las primeras elecciones, con lo cual don Segovia siguió siendo comisionado. Pero para la segunda instancia de 2008 Tincho acompañó tímidamente a un grupo entusiasta que encabezaba una lista opositora, aunque perdieron "por goleada". Pero en esos cinco años hasta 2013, Tincho había cambiado notoriamente. Ya era visto como un posible candidato de peso para la comisión. Solamente no fue elegido por el grupo opositor por su edad (era considerado demasiado joven para ser candidato, con 27 años), pero todos entendían que era el más "sabedor" para gestionar, discutir y ganarse la confianza de muchas familias. Basilio (un profe del colegio), cuyo padre ya había sido comisionado ${ }^{7}$ numerosas veces en los años 60, fue el elegido por su grupo político para candidatearse en 2008, en 2013 y 2017.

¿Qué había sucedido en esos años, desde que Tincho desde sus 20 años hasta pasados sus 30, convertido en un potencial candidato? Una respuesta estaba en el cimbronazo de la resolución 125 en 2008, en esa falsa dicotomía "Campo Vs. Gobierno" (conflicto interburgués generado entre el capital agrario más productivo y el gobierno nacional por el aumento de las retenciones móviles a la renta sojera), conflicto que llevó a Tincho a posicionarse fuertemente, como muchos del pueblo en ese momento, a favor del gobierno de Cristina Kirchner. Pero una segunda clave (y que nadie de sus allegados sería capaz de discernir, por ser tan naturalizado) está en la gestión cultural que Tincho aprendió a realizar durante esos años. Especialmente, en nuevos usos públicos del quichua basado en un medio de comunicación, pero sobre todo en una nueva mixtura entre gestión cultural y gestión política local.

Se trataba de la única radio puesta en el pueblo. La casa, la antena, el cable de transmisión, la consola, la computadora: todos los recursos fueron donados por la semillera multinacional X-Green. Este era un caso "excepcional" para toda la zona,

\footnotetext{
${ }^{7}$ Cabe una aclaración importante: tanto Segovia como Basilio (y obviamente sus padres), y también los comisionados de los municipios circundantes de esta zona centro-sur de la Mesopotamia santiagueña, son quichuistas (bilingües quichua-castellano). En mi investigación de campo he registrado cómo fueron utilizando su repertorio quichua para estrategias de cooptación política o convencimiento "cara a cara" en sus campañas pre-eleccionarias. No obstante, jamás visibilizan estas prácticas ante nadie: no se trata de "vergüenza" sino que simplemente consideran que no es socialmente relevante hacerlo. Esto da cuenta de un modo de hacer Estado por vías muy periféricas, con gran eficacia social y con herramientas que no son propias de lo que se considera frecuentemente como prácticas estatales (Das y Poole 2008).
} 
aunque bastante frecuente en otras provincias donde una multinacional deja "regalías" (como La Alumbrera en Catamarca).

En este caso, se trataba de una "regalía" por el excedente en ganancias en los primeros años del siglo que arrancaba. Cotejaron toda la geografía donde se asentaban sus principales núcleos de trabajadores golondrinas, principal fuerza de trabajo de la empresa en tiempos de la desflorada de maíz. De varias localidades, Llaqta Sur fue la elegida, y la radio fue instalada. Dado que nadie quería hacerse cargo de la radio, se armó una asamblea, donde los vecinos decidieron que la iglesia quedaba a cargo de la radio. El cura de otra localidad (Llaqta no tiene cura propio) aceptó a regañadientes. En los hechos posteriores la iglesia casi nunca tuvo protagonismo efectivo, porque durante muchos años no había cura en el pueblo. De algún modo, la radio devino una institución "civil". Casi no había quién quiera ocupar ese espacio, porque suponía un gasto que nadie tenía, y a la vez nadie se animaba. Desde el primer momento en que vio la radio que se estaba construyendo en 2003, Tincho se vio a sí mismo en ella y decidió que quería ser locutor.

Estamos describiendo el origen y desarrollo de un proceso social, cristalizado en el trayecto de Tincho. A continuación veremos un muestrario de la tensión política subyacente, las dilaciones y las efectivas condiciones materiales que fueron sustentando los procesos sociolingüísticos y a sus hablantes en esta zona.

\section{Las ganas}

Las noticias le llegaban lentamente, sin internet ni televisión por cable. En 2008 y hasta 2011 los periódicos viejos servían a Tincho para ofrecer como si fueran noticias nuevas de ese día. Los contactos, la música pedida por los oyentes (casi siempre chamamé y muy poco de folklore) y sobre todo ese contacto con la gente, hizo de Tincho alguien reconocido. Rápidamente, lo invitaban para ser animador de los numerosos bailes (de chamamé, obviamente, y muy poco de cumbia o guaracha, y casi nada de folklore, porque solamente se lo baila en eventos formales, no sociales). Periódicos, noticias, música, mensajes. La radio se denomina "Pueblo de la Virgen", y tiene una antena con una capacidad de emisión que le permite llegar hasta $60 \mathrm{Km}$. de distancia ${ }^{8}$.

Tincho se enteró en 2006 de que en la universidad de Santiago Capital se dictaba un curso de quichua, que se dictaba todos los viernes y sábados durante un año y medio. Arregló con Anselmo, un maestro, para ir juntos todos los viernes en una moto alquilada a un vecino. Iban a dormir la noche del viernes en diferentes lugares de Capital donde pudieran arreglar (casa de un amigo, una tía lejana, camas disponibles de la Casa del Maestro, etc.). Fue la experiencia más dura que le tocó realizar como estudiante, cubriendo 500 kilómetros de ida y vuelta todas las semanas, 2.000 kilómetros al mes. El dinero para pagarse el curso, combustible y estadía sería costeado

\footnotetext{
${ }^{8}$ Alcanzaba a numerosos parajes y localidades dentro de esa circunferencia: Tala Yacu, Verón, Chilca Juliana, Villa Salavina, Juan Sagol, Mistol Pozo, Taco Totorayoj, Paaj Punku, Santa Lucía, La Bajada, Vaca Human, Noque Paso, Los Telares (cabecera del departamento), El Candelario, Varas Cuchuna, Yacu Hurmana, Sabagasta, Breayoj, Barrancas, Los Tolozas, Los Peraltas, Medellín, Juanillo, Piruas, Los Cerrillos, Rubia Paso, Pozo del Simbol, Real Sayana, Blanca Pozo, Turungun, San Isidro, San Antonio, Anga, Pueda Ser, entre muchos otros. Con la adquisición de nuevos recursos técnicos, el radio de alcance llegó a muchas más localidades.
} 
por el escaso ingreso que le entraba a la radio, dado que él tenía el programa informativo de la mañana, y los comercios de varias zonas pagaban al espacio para auspicio. Había que ponerle más pilas a la locución en la semana, entonces, para asegurarse sus viajes y el curso de quichua los fines de semana. Comenzó a frecuentar su excolegio para pedir prestados libros, de donde extraía poemas para leer en la radio. No obstante, el principal ingreso de Tincho (al igual que casi todos sus amigos y vecinos varones) era el dinero ganado en la desflorada de enero-marzo, trabajando para la X-Green $\mathrm{u}$ otra empresa semillera. Ese dinero siempre era administrado obsesivamente por Tincho: se indignaba viendo a media docena de changos (obreros migrantes "golondrina") borrachos durante días, sentados en el Bar de Corvalán gastándose en vinos la mitad del sufrido pago de la desflorada de 60 o 70 días.

Por supuesto: toda su locución, hasta ese momento, era en castellano, así porque sí. A la mañana le "caían" los viejitos (y no solo ellos) a la radio, para que enviara un mensaje a sus hijos o nietos: que les cuide las cabritas, que no le hagan faltar agua a los pollos, que había encargado con su vecino que anda en moto para hacer llegar a sus nietos dos bolsas de maíz para la chancha.

Estamos en Llaqta Sur. Una mañana de 2007, íbamos caminando con Tincho por la calle, y nos cruzamos con don Mansi (Saturnino Mansilla, 90 años). El abuelo necesitaba que Tincho le enviara un mensaje a su bisnieta mediante la radio (que ella escuchaba). Muchos apodaban a Tincho como "Tinti" (langosta). El sufijo derivativo $l u$ que veremos en la primera línea, indica afecto.

Mansi: Ehh Tintilu munasqa, imayna purisun?

[Tinti querido ¿cómo te anda? (ironía en referencia a su pene)]

Tinti: jajaja don Mansi, orqo sinchi kaq kasa karanki maa?

[jaja don Mansi, viejo duro habías sabido ser ¿no?]

M: Eh Tintilu, ka encomienditá kachachiay, wawitay mikuchinan tiyan kuchicitust

[Tinti, esta encomiendita haceme enviar, mi hijita tiene que dar de comer a los chanchitos]

T: Bueno don Mansi, kachasusaq na utqetu, na Pocho req rin y noqá kutichkasaq

[Bueno don Mansi, ya le voy a enviar, ya sale Pocho (de la sala de operador) y estaré quedando a cargo]

M: Faa ¿qué? ¿jefe na kanki? ¿Te funciona?

[¿ya sos jefe? ¿te funciona? (en referencia al "cargo jerárquico en la radio, y a la vez a su pene)]

T: Enteros kayp okotias purini á!

[Del todo ando ocoteando ${ }^{9}$ aquí yo pues [RISAS]

Como vemos, Tincho ya venía realizando efectivamente interacciones bilingües con otros pobladores: estábamos almorzando, caminando o yo lo acompañaba a sus trabajos, pero la idea de un programa radial-quichua todavía no existía. Tampoco Tincho sentía la necesidad (o la obligación) de contestar a nadie si sabía o no sabía quichua; sencillamente, no había situación que propiciara esa reflexividad en él, y mucho menos en la gran mayoría de los puebleros o "los del campo". Sencillamente, en ambientes ausentes de lenguas minorizadas sin elementos de institucionalidad visibles (escuela,

\footnotetext{
${ }^{9}$ Derivación del quichua oqoti (recto), figuración de fornicación anal.
} 
medios, judiciales, literatura que circule, etc.) no existe la situación propia del objetivismo lingüístico (Voloshino 1929) que ejerce cierta presión en los hablantes para que pongan en la mesa su propia reflexividad y la de los demás. En esos primeros tiempos, Tincho se decía a sí mismo que no sabía mucho de quichua, y me contaba que se sentía muy inseguro (aunque ya vimos cómo se "manejaba" él con un anciano, en una charla "cotidiana" en plena calle). Durante su trayecto en el curso universitario, Tincho fue aprendiendo temas de gramática quichua, literatura regional y algo de antropología. Pero hasta ese momento, no se le había ocurrido que podía articular las dos cosas: el quichua y la radio. Ahí le nació la idea.

Como venimos contando, este artículo trata el período 2007-2014 y parte de 2018-2020. Un programa radial ${ }^{10}$ imaginado por Tincho, llamado Simisniyku (Nuestras voces) fue el principal producto cultural de toda la zona sur de Santiago del Estero: el programa era emitido en quichua/castellano, y sus participantes eran quichuistas ${ }^{11}$. Si bien existen antecedentes de importancia ${ }^{12}$ como la Audición Radial Alero Quichua que se emite

\footnotetext{
10 Yo ingresaba a Llaqta Sur como profesor de lengua castellana en mi primer colegio. Y mis dos primeros contactos en 2005 fueron con Tincho y Pedro (otro obrero "golondrina" que trabajaba para la multinacional X-Green). Pero el contacto más cercano con Tincho y su gente fue mediante un proyecto de voluntariado universitario que presentamos en 2008. Supuestamente, una decena de estudiantes hiciera algún tipo de servicio comunitario desde una carrera, cosa que nunca sucedió porque no había estudiantes dispuestos ni formados a seguir una iniciativa que incluyera al quichua. El proyecto devino más bien en una renovación de recursos para la radio donde trabajaba Tincho (antena, cables, consola, computadora, y sobre todo, un acondicionador de aire para la cabina del operador). Esa colaboración continua a Tincho me permitió seguir de cerca el proceso mismo del programa. Ese acompañamiento fue una de mis primeras experiencias etnográficas enfocadas en un grupo "pequeño". Como decía, esto fue 2008: durante los diez años posteriores sucedieron muchas cosas al interior de la vida universitaria; antes no había en ese espacio una masa crítica con la cual contrastar o exponer datos acerca de "temas de quichua". En consecuencia, el proyecto de voluntariado fue más bien una financiación externa de recursos, y más bien un acompañamiento exploratorio, sin mucha intervención "técnica" de mi parte.

${ }^{11}$ Quichuista es la categoría nativa para el bilingüe (quichua-castellano). Como estrategia históricamente situada -al menos con gran intensidad desde la década del 40- el quichuista se caracteriza por un uso lingüístico singular: el ocultamiento del quichua y el uso de los recursos que dispone del castellano para evitar marcaciones negativas (marginación) desde sector social representado en el castellano estándar, es decir, la mayoría poblacional configurada según los parámetros de la modernización estatal (Martínez 2013) desde mediados del siglo XX hasta la actualidad. Por fuera de cualquier mitificación folklórica, intelectual o culturalista, la categoría nativa quichuista está inevitablemente atravesada por esta configuración estatal-productiva.

12 "Las primeras experiencias radiales datan de 1959, cuando Domingo Bravo inicia un ciclo titulado Ashpap rimaynin "El habla de la tierra", en donde se reproducían diálogos en quichua ideados por Bravo, con grabaciones musicales como complemento. En dichos programas, siempre participaba un quichuahablante, se daba lectura a breves notas culturales y se brindaban explicaciones gramaticales sobre lo escuchado. Es decir, el programa tenía un claro fin didáctico. Diez años después, un grupo de cultores del quichua, Bravo entre ellos, constituyen la Audición Radial Alero Quichua, la que inaugura su primera transmisión en octubre de 1969 y que continúa hasta el presente. En el período de mayor riqueza en su producción cultural, este programa combinaba elementos tan diversos como cuentos y relatos, canciones, adivinanzas, diálogos, todos ellos en quichua, sumados a pequeñas clases gramaticales sobre la lengua. Constituyó una importante fuente de recuperación de la memoria colectiva, de la producción literaria oral, de formas musicales casi perdidas, como la vidala quichua. Además, era un punto de referencia para el encuentro de los quichuahablantes. Gracias a este programa, muchos quichuistas pudieron vencer esa vergüenza impuesta por la cultura dominante, y expresarse públicamente en su lengua materna. Luego de tres décadas de transmisión, producto quizás de un desgaste natural o por
} 
desde hace 50 años en Radio Nacional, y el programa Sachanmanta en la localidad de Brea Pozo (a cargo de un maestro conocido por Tincho y los pobladores de Llaqta Sur), este programa tenía otras estrategias. Simisniyku catapultó a Tincho como agente cultural y posteriormente como agente político de su propio pueblo.

\section{4. $\operatorname{Los} 400$}

Todo fue muy dificultoso para Tincho. Dificultad que duró al menos dos años, hasta que el programa recién despegaría con toda su intensidad en 2009. Esos dos años anteriores "fueron un remar constante" para Tincho por cierta "soledad" en esos programas de domingo a la mañana, de 9 a 11 hs. No había participantes. La lógica del programa se basaba en tratar de leer cuentos de algún manual de quichua, pasar música de Sixto Palavecino (es ciertamente dificultoso conseguir música quichua -registrada o grabadade otros músicos más allá de este artista local ${ }^{13}$ ) y algún comentario (en castellano) acerca de la importancia del quichua y de que "no se debe perder". Es interesante notar que las declamaciones identitarias ocupaban casi la primacía temática, pero no había mucha respuesta en el público. A veces su prima (que es docente en una escuela cercana y daba clases informales de quichua) se sentaba con cierta letanía a leer un cuento frente al micrófono. Decio, un amigo de tantos en el pueblo, lo encontró en la calle un día de semana:

Decio: Eh Tintito, ¿por qué no me quieres invitar para el domingo?

Tinti: Noo amigo, no es así pues, venite el domingo para que veas.

$\mathrm{D}$ : $\mathrm{Y}$ bueno yanasito, rini req pero ancha penqakus, maa yachani rimayta po [Y bueno amiguito, voy a ir pero tengo vergüenza, no sé hablar yo pues]

T: Maa, ama manchaychu chango, ancha fácil kan [noo, no tengas miedo chango, muy fácil es]. ¡Venga usted y deje de calentar la silla al pedo po amiguy! [pues mi amigo (usa el tono de "usted" para ordenar)]

D: Vamos a hacer así, voy a ir con Peñaloza, que quería ir también [a la radio] me ha dicho, no quiero hacer macana yo.

T: No amiguy, mana ruwaq rinki rispá macanast [vas a hacer macanas si no vas]. Le tienes que probar vos qué onda.

De algún modo, no había un "enganche" hacia la gente: el programa de quichua era emitido casi "sin quichua", y Tincho no lograba atraer a nadie. Aunque Tincho sintió que la universidad le "allanaba mejor el camino para pensar las cosas", hasta ahora el formato se basaba en su mirada escolarizada, que él de algún modo basaba en el curso universitario de quichua (y en gran medida en su propia experiencia escolar). Adelanto, entonces, un dato clave: la intuición sociolingüística de Tincho no terminaba de "dar en el clavo". Tampoco se trataba de una idea que puede llegar a confundir: que lo brindado

imposiciones de índole comercial, en las audiciones se observa una declinación del uso de la lengua quichua y una mayor presencia del castellano, especialmente en la música (Albarracín, Alderetes, Pappalardo, 2001, s/d)"

13 Aunque por supuesto hay excepciones. En una ocasión, el operador (que guarda archivos de audio de recitales en vivo, de bailes de la zona) musicalizó con "Sipitas" ("Señoras", chacarera del quichuista Ángel Maldonado de la década del 70), y "Maypichus" (chacarera del conjunto actual "Sachanmanta", quienes tocan folklore pero principalmente chamamé). 
por la universidad no le servía. No es mi argumento ni el de Tincho. Sencillamente, había dos planos muy diferentes de "realidad" sobre la lengua, y no se traba de extrapolar acríticamente un formato de enseñanza formal hacia un formato radial rural. Tincho todavía no tenía en claro (y yo tampoco, en mis registros etnográficos de ese momento) que se trataba de construir un ambiente posible para que los quichuistas pudieran sentirse como en su casa. Esto último es una apretada síntesis que, como una cifra, nos llevó muchos años para comprender todo el proceso tanto en Tincho como en los demás. En una de tantísimas charlas, ya en 2016, rememorábamos: "Hetore ${ }^{14}$, es así, he tratado de que se sintieran como en sus casas, si no, no iban a querer venir; en sus patios de ellos había que meterles la FM... [reflexiona, y segundos después prosigue] no, así era la cosa, el patio tenía que ser la FM". Dicho de otro modo, el patio con frecuencia modulada era la clave.

Algunas ideas fueron apareciendo en 2008. Primero eran estrategias que Tincho usaba en otros momentos de la radio de la mañana, cuando tenía su programa informativo. Por ejemplo, la sencilla idea de pedir a los oyentes que enviaran mensajes de texto, pero que lo hicieran en quichua. Primero tímidamente, y después con más habitualidad, los mensajes iban llegando al programa. Mensajes escritos "así nomás, a lo bruto nomás":

"Ayi pumchau yanasus radiomanta. Cani Julieta Huiñasmanta y iachachina Colegio Secundariomanta. Yachachiara chait saludanaani yachachek Yolanda" [Buen día amigos de la radio. Soy Julieta de la localidad de Huiñas y alumna del colegio secundario. Me enseñó ahí y quiero saludarla a la profesora Yolanda]

(Hérika Chávez, 15 años)

"Yanasui Tintito! Churapay suj temita "maestro rural" iachacheypaj Mari Barredas" 15 [iAmigo Tintito! Ponemelo un temita llamado "Maestro rural" para la maestra Mari Barredas] (William Acosta, 24 años)

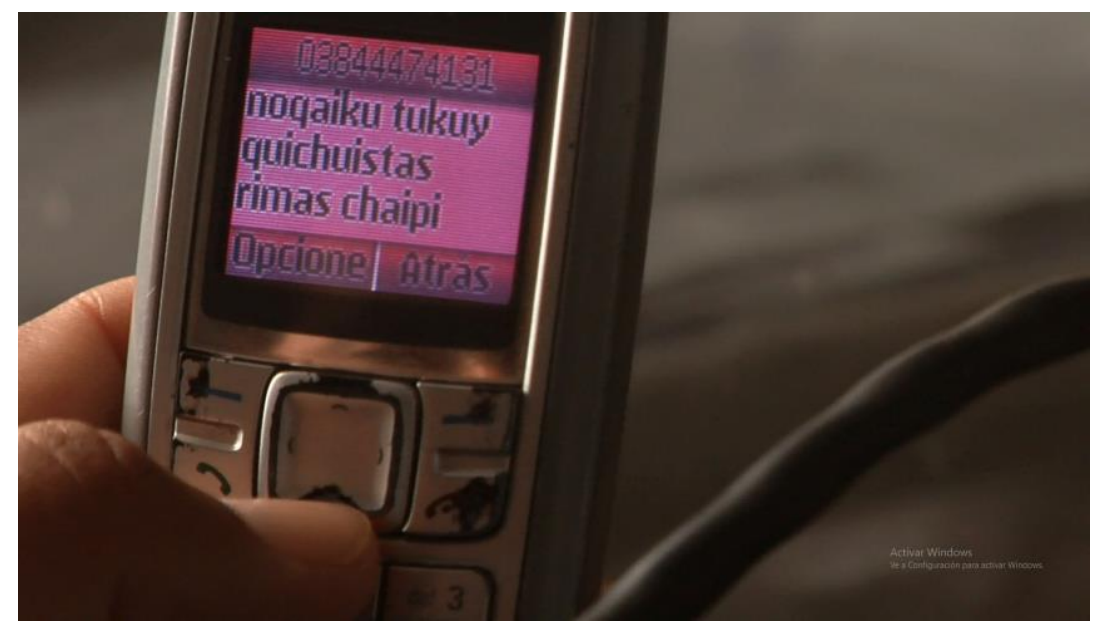

\footnotetext{
${ }^{14}$ Esa deformación de mi nombre, fue el "apodo" con el que muchos me identificaban en el pueblo.

${ }^{15}$ Mensajes normalizados:

"Alli punchaw yanasus radiomanta. Kani Julieta Wiñasmanta y yachachina Colegio Secundariomanta. Yachachiara chayt saludanaani yachacheq Yolanda" III "Yanasuy Tintito! Churapay suk temita "maestro rural" yachacheypaq Mari Barredas"
} 


\begin{abstract}
Mensaje de texto de un oyente en el celular de Tincho.
\end{abstract} La imagen pertenece a un documental (Gerez, 2012).

Tincho (aparece como Tinti en algunos mensajes) se dio cuenta de que leyendo esos mensajes, lograba que llegaran aún más mensajes. La idea en realidad era bastante simple, y Tincho se reprochaba en no haberlo pensado antes. Lo importante es comprender algo que en ese ambiente recién se estaba forjando: que el quichua en la radio no existía, que enviar mensajes de texto a la radio no era usual, que esa dinámica de interacción era nueva para cualquier quichuista que tuviera celular. Y no se trataba de enviar por primera vez un SMS en quichua. Ya lo venían haciendo, pero la interacción era privada: el destinatario era siempre algún pariente o amigo, con un mensaje sencillo que no demandaba mucha atención (guardo decenas de estos sms cotidianos del período 2006-2012, tanto de Llaqta Norte como de Llaqta Sur). Enviar un sms a la radio significaba tener una cierta idea de que debía estar "bien escrito", cosa que casi la totalidad de los quichuistas adultos no conocían. Tampoco había en ellos necesidad u obligación de pensar qué escritura debía tener el quichua. Escribían de acuerdo con lo que su precaria alfabetización del castellano les ofrecía.

Poco a poco, aprendieron a escribir sin pensar en que alguien de la radio les iba a cuestionar o corregir. Tincho hacía su curso de quichua en la ciudad, pero cuando volvía al pueblo nunca se comportaba como un bilingüe normativista o purista. Él solo quería que le llegaran mensajes, no importa cómo. Él comenzó a referirse a sí mismo y ante los demás como un muchacho que no sabe mucho de quichua, que necesita que los verdaderos quichuistas lo ayudaran en el programa. De ese modo fue "obligando" a algunos a que lo ayudaran "porque Tincho no sabe quichua, tiene que ir gente que sepa". Agregamos aquí algo fundamental: el declararse como alguien que "no sabe mucho quichua" allanaba el camino para otros -en clarísima clave agonística, es decir, de desafío- ocuparan ese lugar como "los que saben hablar", primero opinando desde un espacio absolutamente ajeno a la radio, después acercándose para "poner su voz porque Tinti no sabe mucho y yo sí sé mucho de la quichua", y después ocupando ampliamente el espacio del programa mismo.

Una respuesta muy veloz de Tincho, cuando alguien le cuestionaba que no sabía quichua (aunque ya sabemos que sí sabía) era: "Bueno, si usted dice que sabe ¿por qué no va al programa a hablar? A mí me faltarán palabras pero a usted le falta coraje para ir a la radio". Esa respuesta -en términos locales- duele, y mucho. A tal punto que el coraje $^{16}$ (junto con la referida picardía que observaremos en todo el trabajo) es una de

\footnotetext{
16 A una conclusión similar llega Atila Karlovich (2018), en un ensayo muy interesante sobre la Salamanca (en un prólogo a un libro quichua de José A. Sosa). A diferencia de estudios anteriores, Karlovich llega a la conclusión de que la Salamanca no se estructura según el pacto europeo (donde hay un negocio de intercambio entre el alma y un don que el diablo ofrece), sino que aquí solo se necesita el coraje de entrar al pozo. Ese coraje es privativo de hombres. Y la currícula salamanquera (2018: 31) se compone de saberes como el manejo de armas, la doma, el conocimiento de la caza, el baile y la ejecución de algún instrumento. En la Salamanca local el aspirante no pide dones de dinero ni riquezas, sino los medios materiales para obtenerlas. Como dato: resulta muy interesante la oferta curricular salamanquera que Karlovich consigna, porque se trata de saberes propios de la trama militar-agraria de mediados y fines del siglo XIX. Es la misma trama social, nítida, la que aparece en la primera obra quichua de José Antonio Sosa (Pallaspa Chinkas Richkaqta, Juntando lo que se va perdiendo, 1953). El
} 
las claves culturales de estos territorios. A don Segundo (maestro jubilado, quichuista "de ley") le dolió tanto esa respuesta que dejó de hablarse con Tincho durante un tiempo. En otra ocasión, Tincho lo volvió a arengar, y don Segundo comprendió que lo que realmente hacía Tincho no era atacarlo, sino pedirle ayuda.

Del mismo modo en que le enviaban mensajes de pedidos, así le llegaban a este programa, pero en quichua. Tincho decía que él estaba para servir a la gente con los pedidos. Ya no llegaban "saluditos" en quichua, sino mensajes serios con urgencias o pedidos familiares con cierto dramatismo. El discurso quichua "escrito" se iba expandiendo mediante la radio:

"Willaykish yojsiscanta chunca animales cabríos huasiita chaiaranku caipi apicuni wishcas corralpi. Dueño uiarispa amus pusachun. Firma Jacinto Yacu Urmanamanta"

(Comunico que salieron diez animales cabríos [que están] perdidos en mi casa y aquí los tengo encerrados en el corral. Si escuchas el dueño, que venga a llevarlos. Soy Jacinto de Yacu Hurmana)

"Huillacunani hurman sirisqanta suj animal vacuno maiu ucupi kainaman pacha tian, dueñoan uiarispa qemicuchun. Kani Shamu Toloza, Huiña Yacumanta"17

(Comunico que está caido un animal vacuno dentro del río desde ayer. Si escucha el dueño que se arrime, soy Shamu Toloza, de Huiña Yacumanta)

Decio se decidió. Entró por primera vez a la radio. No lo hizo solo. Vino acompañado de un anciano, don Anush (Arnaldo Gómez, 94 años) que estaba escuchando el programa en su ranchito, a 15 kilómetros del pueblo. Decio fue a buscarlo en la enduro Yamaha de 250 cc., y don Anush se acomodó detrás de la moto con su bastón, su sombrero y una mochila vieja (llevaba patay de algarroba y bolanchao de mistol para invitar). Antes de salir, estando arriba de la moto, se largó con un sapukay (grito estético) de chamamé, ante la mirada atónita de su mujer anciana y sus nietos riéndose a carcajadas. Con sus piernitas flaquitas, otros dos vecinos ancianos lo "chanceaban" porque con su bastón don Anush parecía kimsero (cabrilla de tres patas). Ese sapukay lo delataba en su alegría de ir a la radio por primera vez.

Llegó junto con Decio, y se acomodaron en la sala de operador donde Tincho ya había comenzado. Decio me dijo después que le temblaran las manos cuando se animó a tomar el micrófono por primera vez, para hablar con don Anush:

Decio: Y don Anush, cuentemé, qué tal paqarinki, munasqa viejito Tala Pujiomanta, niay imayna tiyanki, imat añus tiyasun, enteros uyareqkuna uyariachkanku. Noqá

escenario descripto es, precisamente, la vida rural-militar de mediados del siglo XIX. De algún modo, y como vemos en los diálogos, los participantes juegan y refieren mucho esos mismos temas. No se trata de que los reproduzcan del mismo modo (aquí no hay ni soldados, ni figuras laborales perimidas como "agregados" o "conchabados") sino que el ambiente agonístico de hombres los habilita a medirse en esos conocimientos, y cuya práctica viene consolidada desde hace muchísimas décadas. Parte de esta configuración social es sumamente importante para comprender el quichua.

17 Normalizado: "Willaykish lloqsisqanta chunka animales cabríos wasiyta chayaranku kaypi apikuni wichkas corralpi. Dueño yuarispá amus pusachun. Firma Jacinto Yaku Urmanamanta” / Normalizado: "Willakunani urman sirisqanta suk animal vacuno mayu ukupi kaynaman pacha tiyan, dueñoan uyarispa qemikuchun. Kani Shamu Toloza, Wiña Yakumanta". 
wamaq kutis kas kaypi [qué tal ha amanecido, viejo querido de Tala Pujio, cuente cómo anda, cuántos años tiene usted, todos los oyentes nos están escuchando. Es mi primera vez frente al micrófono aquí] (Decio se pone en el lugar de un entrevistador, y nótese que las preguntas no funcionaban como él esperaba)

Anush: Y bueno... (pasaron 10 segundos) (no se anima)

D: Ahh ancha manchachiara cha micrófono. Suk vinitó sumaq kanman kara, manash?

[Decio se da cuenta y cambia de estrategia -Ahh mucho miedo le tengo a ese micrófono. Un vinito habría sido mejor ¿no es cierto?-]

A: Chayna qam nis, pero saanp motó ancha chakikunaaspá pureraysh [Vos así dices, pero arriba de la moto muy queriéndonos secarnos hemos venido] [risas] (don Anush se relaja con esa picardía <con sed por la falta de vino>)

Tincho: Sumaq punchaw don Anush, qaachiay brasusniykit ancha sinchi, yantayna kas kaq kara [Buen día don Anush, muéstreme esos brazos tan duros, como troncos habían sabido ser] (referencia al duro trabajo, aunque don Anush es muy escuálido)

\section{(Decio se seca las manos transpiradas por los nervios)}

A: Ancha agradeceyki Tintilitu. Que tal paqarinki yanasusniy locutorés, noqa cani suq kari ancha unay pureq...Kani kichwa rimaq. Radiuykiman amuni visitasoq, ancha kusikus ka programaykita ancha sumaq kasqanta. Kusikuni y ojalá chayna ñawqeman riy mana ka kichwaysh tukukumanta. Familiaresniy nianku 'Walu' y apini 94 watast". (Qué tal amanecieron amigos locutores, yo soy un hombre que anduvo mucho. Soy quichuahablante y vengo a la radio a visitarte y me alegra mucho tu programa, que es muy lindo. Me alegro y ojalá sigas adelante para que nunca se termine nuestra quichua. Me dicen de apodo "Tortuga" y tengo 94 años)

Llegó Digush, el director de Las Sierras; Mari, una maestra; José, agente sanitario; Pedro, amigo de Tincho que es obrero golondrina, y cinco muchachitos más que no recuerdo (también obreros golondrina). Tincho no podía creer que se acercara gente, gente cercana, todos amigos suyos y vecinos. Algunos se acomodaron parados en la ventana de la radio, otros quedaron parados en una sala, mirando por la ventana vidriada conectada a la sala de operador donde estaban sentados los tres con el micrófono. Minutos después entró un mensaje de una de las nietas de don Anush, que tenía 7 años, y que decía lo siguiente.

"Que tal purinki yanasuy Tincho. Cani María Talapujiomanta. Cani suq nietat y ancha cusicus tiani uiaris abueloyta" ${ }^{18}$ [Cómo andas amigo Tincho. Soy María de Tala Pujio.

Soy una nieta y estoy muy contenta escuchando a mi abuelo]

-Ay wawalay, saqritay! [¡Ay mi hijita amada, mi fierita!]

Don Anush comenzó a lagrimear. Todos los presentes estaban visiblemente emocionados. Después de dos años de idas y venidas, de no "embocarla", Tincho vio que el programa había hallado su sentido.

Comenzaron a llegar mensajes que podríamos caracterizar como identitarios. Eran los mensajes más numerosos: como veremos en toda esta investigación, funcionan a nivel

\footnotetext{
${ }^{18}$ Normalizado: “Qué tal purinki yanasuy Tincho. Kani María Tala Pujiomanta. Kani suk nietat y ancha kusikus tiyani uyaris abueloyta"
} 
identitario (superficial, si se me permite el término) pero no reflejan el estado real de prácticas efectivas de la lengua en tiempos actuales. Uno de los discursos más reiterativos de todos los participantes frente al micrófono y oyentes frente a la radio, era la declamación del rescate del quichua para que no se pierda. La "cosa" identitaria, aquí, es siempre referida como llamado a revertir (siempre románticamente) el desplazamiento lingüístico. Guillote, por ejemplo, es maestro en Chañar Pozo $(30 \mathrm{~km}$. de Llaqta) y llamó a la radio el domingo posterior a la visita de don Anush:

\begin{abstract}
Tincho: Cuentaay imayna purinki yanasu, maypi purinki kunallitan? [Contame amigo cómo andas ¿dónde andas ahorita?]

Guillote: "Que tal purinki, yanasuy Tinti, anchami kusikuni tiyaptiy kaypi, entero uyareskuna saludakiysh. Noqa Llaqtamanta kani, tukuy kichwata rimayku utulaman pacha, y Sierraspeqa cha maypi yachachini wawitas kichwata rimas wiksamanta lloqsinku, tatasninku na unay penqakoq rinku rimayta, pero kunanqa cha na chinkachkan y tukuy noqaysh kawsachinaysh tiyan ka qellu layata munaysh, cha kichwa nipunku chayt. Mana cha unayrayku yachacheqkuna waasta maqakoq karanku kichwapi rimaptinkuna, y kunanqa mana maypij kachun atis rimayta y noqayku ka proyectoan "Sapisniyku yachachianku". Atinku niyta ancha sumaqta riasqaykuta, waas y noqaycu yachacheq kuska yanapanakus kichwapi rimayku" [Qué tal andas amigo Tinti (Tincho), estoy muy contento de estar aquí, y saludo a todos los oyentes. Yo soy de Llaqta, desde niño aprendí quichua desde que hemos salido de la panza. Hace mucho nuestros padres tenían vergüenza de hablar, pero eso ya se está perdiendo, y todos nosotros tenemos que hacer vivir queriendo nuestra lengua, a eso que le decimos "quichua". Eso antes no les enseñaban, a los chicos los pegaban cuando hablaban en quichua y hoy no. Donde sea pueden hablar y nosotros con este proyecto aprendemos nuestras raíces. Podemos decir que nos va muy bien, los niños y nosotros, los maestros juntos ayudándonos hablamos en quichua].
\end{abstract}

He transcripto solo una de las declamaciones de este tipo, que fueron excesivamente reiterativas. Nótese que en su contenido se cifran varios temas que son los más frecuentes: la vergüenza, la prohibición en la escuela, el origen materno de la lengua, la resistencia para hablar, y la idea de que en la escuela -supuestamente- se estaría trabajando positivamente con el quichua. Digo "supuestamente" porque no existen cargos formales de quichua, y las experiencias son muy asistemáticas y no se replican o sistematizan hacia un desarrollo más objetivo en ninguna de las escuelas de la zona, paradójicamente, compuestas de una mayoría de alumnos quichuistas.

En una de esas charla "operativas" con algunos amigos, pero sobre todo entre Pedro y Decio, surgió la idea de un concurso de adivinanzas. Tincho consiguió un auspicio: la carnicería del Rengo Peralta iba a donar 2 kilos de asado para la mejor imasimariasima (se le dice así a las adivinanzas). El Rengo era un declarado opositor al comisionado, y ya había escuchado que Tincho -en uno de sus programas informativos de la mañanahizo una crítica por el estado de los caminos (sobre todo, el camino lleno de bobadales, ese barro pegajoso, que lleva a la casa de la madre del Rengo, a 10 kilómetros de Llaqta). Así, el Rengo decidió acompañar a Tincho con el auspicio.

Suk adivinanzata kachasuyki: "yakup yaykun pero mana oqon" (la sombra) [una adivinanza te envío: entra en el agua pero no se moja] 
Rosa, 12 años

"Chichus malayan, wachas mansayan" (la escopeta)

Segundo, 13 años

Na suk adivinanzata kachasuyki: "Sachap qaparin, pampap upallan" (el hacha)

[Ya te envío una adivinanza: grita el monte, se calla la pampa"]

Anselmo, 20 años

Imat kan? "maman palta, waa muyu" (el quimil, un tipo de cactácea)

[¿qué es? La mamá ancha, el hijo es redondo]

María Jesús, 18 años

"Yakuman ris waqan y voliakus ina waqan pero yakut mana upyan" (el cencerro)

[al agua entra llorando y sale llorando, pero no se moja]

Marcos Díaz, 40 años

Las respuestas no tardaron en llegar al programa siguiente. Tincho iba leyendo las adivinanzas pero sin decir su resolución. Los mensajes se multiplicaban para acertar no solamente con la adivinanza más linda, sino también con la resolución de cada una. Tincho comenzó ese día a las 10 am, y para el mediodía ya tenía 400 mensajes con adivinanzas. Esa tarde estuvimos leyendo su celular, y resultaba sorprendente que más de la mitad fueran emitidos por adolescentes o niños (mensajes normalizados).

\section{Shisha}

Cuando escuchaba que hablaban en quichua, "para mí fue ya...así como que... algo que me ha caído re bien". Shisha no encuentra palabras, mirando hacia el techo. Después de tantos años, imaginaba que era una forma de "recuperar" el quichua, como si estuviera perdido, pero no para los que hablaban quichua, sino para los otros. Ella pensaba en sus chicos que estaban creciendo recién. Se ilusionaba con que ellos escucharan qué significa eso de hablar, así, en la radio a viva voz. No puede describir su sensación cuando escuchó por primera vez el programa. Para ella "muchas mujeres escuchan de modo normal", pero me dice que siente diferente esa escucha. Hasta que un día se animó, estando acostada a la siesta. No se cansa de contar a quien quiera escuchar, que una situación particular la motivaba y la bloqueaba a la vez: es mujer. Le daba no sé qué porque iba a ser la única mujer en medio de hombres. ¿iba o no iba? Y se animó. Se levantó, arrancó la moto y se fue. Y me enfatiza "pero así... de una, me fui".

-Imaginate Hetore, en la radio, estaban. Primero me miraron medio raro, porque la única mujer que a veces anda es doña Jacinta, que es muy ancianita y la traen desde Villa Taqo. Nunca habían pensado que una mujer joven iba a meterse en la radio-. Como veremos no solo aquí sino en otros ámbitos públicos, es muy poco frecuente que participen mujeres jóvenes, porque no entra en el casillero. Para ser mujer quichuista, ineludiblemente debe ser vieja, porque si no, no representa bien ese "reservorio" lingüístico. No hay otras mujeres, y mucho menos que sean jóvenes.

Una mujer de unos 37 años en medio de hombres. Y con un marido que no miraba con buenos ojos esa iniciativa. Pero había algo más en ella: esas ganas de querer hablar en 
quichua, porque "no sentía nada, con la cabeza en blanco me mandé, y así entré". Para Shisha se trababa de enfrentar: no se trataba solamente de ser mujer, sino de hablar quichua enfrentándose a todo aquello que ella había creído establecido, y que nunca lo había reflexionado con nadie: el quichua, cuando era lengua pública, era lengua de hombres.

Una forma diferente de observar la picardía agonística: Shisha, antes de "mandarse a enfrentar", sabía que tenía que hacerlo desde un lado no violento. Tenía que pero ir con buen humor. Algunos conocidos la "agarraban", la criticaban para varios lados: sea porque el programa radial era en quichua y no era frecuente que lo fuera, y porque las primeras "críticas" -en la calle- a la propia Shisha eran también en quichua. Tincho me contaba que a ella le decían: "ehh, qué tiene que hablar la Shisha ahí". Cosa de hombres. O una forma eficaz de que se aseguraran esa picardía agonística, que parecía ser exclusiva de hombres. Pero también recibía saludos de aliento. "Shishila ${ }^{19}$ querida, vos le tienes que hablar, tienes que hablar, tienes que hablar", me repite en medio de unos mates. Una sobrina la arremetió con "hablale en quichua, que se caguen esos viejos chotos, yo te voy a escuchar". Lo interesante del caso es que Dalmira, su sobrina, en el colegio era terriblemente negativa hacia el quichua de sus compañeras "del campo" (aun siendo ella misma una quichuista), y jamás se interesó por la materia de "quichua" durante los 5 años de cursada en el secundario. Pero quería mucho a su tía: por la vía de una incipiente intuición de género, ella alentaba a su tía a que no dejara de ir al programa radial.

-Para mí era algo [pasaron más de 15 segundos muy extensos]... sorprendente, porque era agarrar un micrófono y hablar-. A Shisha le cuesta contarme, hay una sensación de intromisión en un mundo nuevo que ella jamás había imaginado estar: "para mí era algo como que... ni te digo, no te puedo decir ni de qué color estaba, no sabía si era rosa, roja, o negra" y nos reímos a carcajadas. Shisha tenía 40 años, es bastante esbelta (de un cuerpo muy infrecuente en comparación con las demás mujeres) y tiene una larga cabellera negra con trenzas. "Agarrar el micrófono era como que veía en multicolores cuando participaba".

Shisha se posiciona como una "mujer de campo, campo, campo". Cuando estuvimos en una celebración del 25 de mayo en 2010, ella -hacia los demás- portaba solamente ese rostro de sorpresa solo como puede tenerlo con ella misma. Porque jamás habría pensado participar en el jardín, como una mamá que recita un poema en una fiesta patria. Pero ante varias mamás que abrigaban a sus chicos, Shisha no dejaba de repetir que "hay que animarse". Ella se refería a ese acto, a ese intento de hablar ante la gente. Otra vez, había que "enfrentarse". Llevó una poesía escrita mentalmente esa vez. Restregándose las manos por el intenso frío de ese día, comentaba divertida su "presencia" con sombrero y poncho, ante las risas de los demás. Días después, su tía me contaba orgullosa de su sobrina, que su "método" para el poema del 25 de mayo fue componer mentalmente, y después a papel "y le borraba, le agregaba, le borraba nuevamente" (risas) "así estaba, hasta que me salió. Todo en castellano. Pero lo escribí sola". Su sobrina vio cómo Shisha se quedó despierta, componiendo, en la madrugada

\footnotetext{
${ }^{19}$ El sufijo - la es un derivador isocategorial que connota afecto con intensidad, aplicado a un sustantivo, o en este caso, a un nombre propio.
} 
previa al acto. Porque había que animarse. El acto se enmarcaba en los festejos nacionales del bicentenario de la revolución de mayo de 2010, y la escuelita del jardín fue la organizadora: de toda la zona habían llegado contingentes escolares, agrupaciones gauchas, equipos de fútbol, un contingente policial y varias delegaciones de Ong's asistencialistas. Shisha creyó que todo el "campo se venía al pueblo, porque esas cosas de tradición venían del campo, no del pueblo". El marido de la directora de la escuela se reía porque ella estaba con que escribía esto, que le borra esto otro, al rato borraba este otro, no, ahí no va. Y así cerró por fin su poema alusivo a la fecha.

Ese método compositivo le fue muy útil en la radio. Después de participar gradualmente en la radio, Shisha se puso a escribir. Guarda varias hojas de relaciones y aros en quichua, cosas que debía contestar a don Segundo, que era el más pícaro y "sucio para hablar; ["elaboraba aros y relaciones en mi casa"] era más para darles de una, así, a los hombres" (risas). Shisha me contaba así su propio método para responder a las interacciones agonísticas que se establecían entre los hombres: ella debía responder con velocidad y eficacia ante cada "ataque". Tenía que ser lista ante las "malas palabras" de ellos. Nótese la "velocidad", esa adrenalina que Shisha sentía y que jamás pudo decírmelo en palabras (fragmento desarrollado en solo 20 segundos):

-Don Segundo: Cha chayta amun, ka chacarera versosnian Martín Fierropa, cantasqa por el amigo Pilliku [eso eso ya viene, esta chacarera con versos del Martín Fierro, por el amigo Pilliku].

\section{[música]}

Don Segundo: Rini contrapusoq Shishita suk imasimariasimata [una adivinanza te voy contrapuntear]: "con el pico picotea, con el culo tironea" [la aguja]. Segunda parte, ishkaq qemikuchkan de chacarera Martín Fierrollapa! ¡Meta nomás! [la segunda parte se me acerca de la chacarera de Martín Fierro]

-Shisha: Astaan sumaq nis kichwapi Arut [es más lindo cuando dicen el Aro Aro en quichua]: "mozo de veinte novias/conmigo será veintiuna/ si no te casas conmigo/no te casarás con ninguna".

Shisha guardaba un librito de rimas y aros que le había pasado su vecina. Transcribía las coplas y las editaba: cambiaba, sacaba o agregaba palabras. Todo para salir airosa cuando se les enfrentara.

Cuesta mucho animarse. Porque Shisha "le venía escuchando hace mucho", me insiste con que le encantaba escucharlo. Pero sigue sin encontrar las palabras para decirme "eso": lo que no puede decirme es, precisamente, las ganas de estar. Porque "soy, como te digo, que de juntarme con alguien que habla quichua. Yo como digo siempre: mis hijos se han criado, entienden todo quichua pero no son de hablar casi. Uno que otro te entienden, SÍ HABLAN ${ }^{20}$, pero no hablan lo mismo que yo. Hasta mi marido, él es también nacido y criado en el campo, pero hablarte en quichua, NO". De las muchas veces que hemos hablado, y cada vez que recordamos sus comienzos en el programa, Shisha reitera sus "cómo te digo", "no sé cómo decirte".

\footnotetext{
${ }^{20}$ Como ya sabe el lector, la marcación con MAYÚSCULAS representa la intensidad forte en todo este trabajo.
} 
Para ella, tomar un micrófono era cosa de miedo. Cuando ella vio que iban llegando mensajes de texto al Nokia desgastado de Tincho, sentía que estaba haciendo algo más que útil, atendiendo mensajes. ¿Cómo habrá sido para ella saber que la gente de Añatuya escuchaba (a $70 \mathrm{~km}$ )? Una vez en las Trincheras (carnavales) de febrero, una familia de Quimilioj (a $55 \mathrm{~km}$.) se le acercó y le preguntaron ¿vos sos Shisha, de la radio? Y Shisha se ríe contando la anécdota en la misma radio, ante los oyentes de invierno de 2011. Ingenuamente se desconocía en su propia voz, pero todos la reconocían al instante.

¿Y cuándo van a volver a estar? le preguntaba doña Agi (Agenora), fiel escucha del programa, sentada en su ranchito a 10 kilómetros del pueblo, en medio de un descampado salitroso y del viento caliente. Y Tincho siempre tenía que estar atento a contestarles: bueno doña Agi, más adelante vamos a hacer el programa. Ya para 2014 Shisha se pone nostalgiosa, porque el programa fue cayendo lentamente en frecuencia. De hacerlo semanalmente, pasaron a hacerlo cada dos, tres domingos, y después cada dos meses. El motivo del "declive" no estaba en los oyentes, los participantes o en algún problema interno. Simplemente, el efectivo promotor cultural, Tincho, era el nuevo secretario de la municipalidad, y la tarea política le demandaba todo el tiempo. Desde 2013 en adelante, el programa radial ya casi no existía. Con los años, Tincho fue dejando de prestar atención a cualquier interlocutor que tuviera al frente ("parece que ya ni pelota te da, embobado con el celular está las 24 horas, ni duerme", y así en la calle, en su casa, con los vecinos), para dedicarse a contestar, a discutir, a organizar todo lo que le llegaba al celular (todavía no había smartphones). Ya para ese año de las elecciones de 2013 en que ganaron, Tincho vivía frenéticamente con el celular. Se acostaba a las 3 am y se levantaba a las 7am para ir a la municipalidad. Vivía con los ojos rojos y la cabeza siempre pensando en números, en gestiones, planillas para completar, viajes a la Capital a "pedir" cosas, entre muchas otras tareas.

Shisha me cuenta que un día de agosto de 2016 se fue a la radio, porque tiene una amiga que trabaja ahí a la mañana como operadora, "y miré la sala de operador, miré la computadora, y vi un celular que recibía mensaje -y me daba no sé qué ver el micrófono, la nostalgia será", me dice entre risas. Y le recriminaba a Tincho que -¡cómo no vamos a hacer de vuelta el programa che!-. "Cuando Tincho descanse y duerma una noche, va a hacer el programa; sé que no es fácil para él, pero todos queremos volver a estar ahí", me decía Shisha. Y otra vez refiere sobre esas ganas -Te juro que venía al programa, así de una, te juro. Me dio no sé qué, digamos, porque me acosté una día a escuchar el programa. Y NO PUDE ESTAR [aguantarse de participar]. Y me vine. También muchas veces, cuando dijo doña Titi, la maestra, cuando dijo que se podría hacer un escrito que salga de alguien. Algo de alguien. Y también así se me ocurrió ponerme a escribir algo para el programa. Y lo hice. Pero ya era otra cosa cuando me vine a la radio, porque me ponía a escribir los AROS. Era más que nada para ponerle humor al programa. Hacerles sentir bien, porque la gente se mata de risa escuchando. Es PONERLE MÁS HUMOR AL PROGRAMA [me dibuja con las palmas de sus manos, en posición horizontal, como tendiendo un mantel desde el centro hacia los costados]-. -Pero hay gente que cuestionaba el programa ¿cómo lo ves vos a eso? 
-Y... las malas palabras, del Rumitu (Rómulo). Ese chango es más mal hablao que el Zupay en pedo ${ }^{21}$. Porque yo siempre he dicho aro aro, pero AROS SANOS. No mezclando malas palabras, tampoco me iba a gustar mezclar con malas palabras. El tema ese [sobre las malas palabras]: yo tenía razón. Ese tema no va y punto. Sí, por ahí, a muchos les gusta eso, a la gente del campo. Pero a la gente del pueblo mucho no les gustaba que hablen así, con malas palabras.

Viticu: Ancha sumaq cha macetitu [muy lindo ese -chamamé- maceta] Rumitu: cada vez que voy al baile/ me andan llamando corneta/ con esas ancas paridoras/ me has hecho correr la jeta [CARCAJADAS]

Segundo: (festeja el aro) ¡Igualllat pumayna kanki! [Sos igual nomás que el puma!] Contestapuy Shishita [contestale Shishita]

Shisha: Responde con otro aro en castellano "se pasa de andariego/ muy cambiador de mujer/ que yo soy mujer casada, y no le puedo atender" [Risas entre todos]

Segundo: ¡Que venga la que falta!

[Tocan la segunda parte de la chacarera "La vaca mocha", chamamé de Pastor Luna]

Segundo: Ancha sumaq, suk chinita Barrancasmanta dansachkan, gato quiere ser [una chica de Barrancas está bailando]

Shisha: Imamant reqsinapunki ¿De qué lo conoces [al gato]?

Segundo: De las ancas. Bueno, gato va ser, que venga nomás, mana chusapunanpaq! [ipara que no le falte!] (se refiere a la parte que falta de la canción)

(Tocan ahora un gato de Sixto Palavecino. Termina la primera parte)

Segundo: Shisha, cuando tu vestido se va/ yo solo miro la luna/ si me dices que sí/ ya no la miro a ninguna [RISAS]

Shisha: viejo chivo mana qollqe ${ }^{22} / q u e ́$ me quieres atajar/vos no tienes ni calzones/ y me quieres piropear" [CARCAJADAS por la salida de Shisha]

Al igual que varios puebleros seguidores del programa reflexionaban, "adentro del pueblo nadie escucha, pero las casas a los costados del pueblo sí escuchan radio, y de ahí todos los de afuera, sí, todos escuchan. Pero aquí en el CENTRITO NO ESCUCHAN -enfatizaba Shisha-, a una vecina mía poco le agradaba escuchar a grosso modo lo que se decía".

¿¿Pero por qué no les gustaba?

-Porque la radio es de la iglesia. Por ahí viene la cosa [el cuestionamiento al programa]. A veces no le puedes ni poner los cuentos de Pochi Chávez, que es un humorista que recorre el país, y sin embargo aquí se quejan de que lo pongan. Y en todas las radios lo están pasando ¿por qué aquí no? Con todo lo que pasan en la radio de los otros pueblos cercanos. Todo esos pasan [se refiere a audios de Pochi Chávez] pero por ser parte de la iglesia no te dejan. No hay un cura como corresponde, los que vienen ahora son como los evangélicos, porque muy mal trabajan. Yo a varias viejas les he escuchado

\footnotetext{
${ }^{21}$ Más atrevido que el diablo borracho.

22 "sin dinero" (traducción). La frase correcta es mana qollqeyoq, pero Shisha recorta la palabra para cerrar el verso.
} 
CRITICAR EL PROGRAMA. Y lo más complicado es que... no hay otras mujeres para que participen. Así como yo, no hay. Porque el otro día Tincho andaba por allá (el campo) y le dijo a una chica "vos hablas bien en quichua, no te animarías a ayudarme en el programa?" Sería como [que habría que] capacitarla primero. Eso dijo: "no, no, no estaría [preparada] ni para dar mi nombre". ¿Y eso por qué puede ser? Decía "yo estaría hablando pero no quiero que me digan mi nombre en la radio". ¿Por qué no quiere ella? No lo sé-.

Sin embargo, un rol importante para Shisha fue como mediadora. Cuando iban niños de visita al programa, llevados por sus maestros o padres, ella era la más adecuada. Don Segundo con sus 70 años y su vozarrón, no era el más indicado para hablar con los chicos. Tincho, si bien era la el "conductor" del programa, tampoco lograba esa confianza con los seis chiquitos que habían llegado con su maestro desde Las Sierras. Afuera estaban inquietos y bromeaban con Tincho; adentro en la sala de operaciones, ninguno quería hablar. Shisha los acariciaba y los fue hablando, conformados en un semicírculo de la sala de operador. Hubo una broma y todos rieron:

Digush (maestro): ¿Se acuerdan que jugábamos a hacer periodismo?

Marcelo (10 años): Eh, vamo a hacerse que nos entrevistan.

Tincho: Muy bien, yo les voy a preguntar entonces: "Imayna tiyankiysh yanasuskuna, ancha kusikuni amusqaykiyshta kaypi radiuman" [Cómo están ustedes amigos, muy contento de que hayan venido aquí a la radio], y ellos le contestaron:

Rodrigo (10 años): Alli punchaw, noqa astaan kusikuni chayas tiyasqayt kaypi qamwan y chayna noqa yupakuni ka qallu mana chinkananpaq [Buen día, yo más me contento al estar aquí con vos, y así yo me sumo para que esta lengua no se pierda]

Antonio (6 años): Alli punchaw, kani Antonio Pujiomanta y apini shoqta años. Kunan kawsani Sierrasmanta y tiyani ancha kusikus rimas radiupi. Noqa mana penqakuni. (Buen día, soy Alfredo de la localidad Pujio y tengo 6 años. Vivo ahora en Las Sierras y estoy muy contento hablando en la radio. Yo no me avergüenzo)

Tincho: ¡Eh ancha sumaq! [¡muy lindo!] Bueno, sigamos jugando a que nos hacemos entrevistas. Entonces les pregunto: imapaq kichwat sirwinchu qamkunapaq? ¿Para qué les sirve el quichua a ustedes?

Clara (8 años): "Kichwap kan noqaykupaq suk qallu kukunamanta burlakunaypaq, y ancha asikuyku uyaris paykunat, mana yachas kichwata rimanku allqon troteninan" (el quichua es para nosotros una lengua que también nos sirve para burlarnos de los otros que no saben hablar en quichua, y nos reímos muchos también cuando ellos no pueden hablar, y hablan cruzao como trote de perro)

Los puebleros no se enojaban porque esos diálogos en quichua estaban compuestos de cuentos y palabras subidas de tono, sino porque ellos entendían perfectamente lo que en la radio se estaba dialogando en quichua, y temían que escuchando esas palabras, sus niños y jóvenes aprendieran "malas palabras". Es la radio de la iglesia, sí, pero el registro de lo dicho en quichua no es solamente para los de "monte adentro". Ya para esta instancia, muchos oyentes del "monte" sintieron realmente que ese era su programa.

Entre febrero y mayo de 2011, las inundaciones alcanzaban niveles históricos. Pido al lector que recuerde el drama de las inundaciones que refería al comienzo. Es realmente importante: más allá de la organización desde el municipio y Defensa Civil para ayudar, 
entregar víveres, colchones y evacuar a las familias, el programa radial se convirtió en un canal de descarga y de contención para decenas de familias aisladas por el agua. Hablarles en quichua era mucho más que darles fuerzas. Por eso para Shisha es indescriptible lo que sucedía en la radio.

Llamaron a un amigo maestro, Samuel, que se encontraba aislado con 15 familias por la inundación:

Tincho: ¿Qué tal andas amigo?

Samuel: ¿Cómo anda usted?

Tincho: Muy lindo están golpeando aquí [en referencia a los músicos]

Don Segundo: ¿Qué golpean? No es burra eso [risas, picardía de don Segundo].

Tincho: ¿Te preguntan qué golpean?

Samuel: Guitarra, qué otra cosa va a ser, aunque Mario Don Segundo es muy gaucho.

Él era también golpeador.

Don Segundo: Na nerayki yanasu, ancha unay caballuy wañopara [ya te he dicho, amigo, mi caballo hace mucho que se me lo ha muerto] [RISAS en la cabina]. [hace referencia a su pene, pero lo dice en quichua]

Samuel: Eh amigo, no te escucho bien, aquí estoy con mucha agua. [Samuel no sigue la broma del caballo porque -supuestamente-, habría ruido, y sigue hablando en castellano para mantener el canal].

Don Segundo: Eh amigo, mandame algo de agua para aquí. Me han dicho que Dalmiro (un vecino de Samuel) está lleno de agua. Esa camioneta que tienes no vale ni diez pesos. ¿Qué le haces decir?

Samuel: Con tanta agua dice que vamos a hacer gaseosa [RISAS].

Don Segundo: Te mando saludos, y saludost, ka sipita, jardinp yachacheqmanta. Ancha ojitos apinki, qamrayku noqapa kan, y chaytayki mana kan. Armachikuy, pero karullamanta, qam ancha peligroso kanki [saludos para la señorita, la maestra de jardín. Tené mucho ojo con esa maestra, porque ésa es mía, y no es tuyo eso. Hacela bañar, pero de lejitos nomás, porque vos sos muy peligroso] (Don Segundo sabe que la maestra viene de la ciudad y no habla quichua; por eso no dijo esto en castellano)

Samuel: Qosanta apin cha warmé [tiene marido esa mujer].

Don Segundo: No importa hermano, todo tiene solución en la vida [CARCAJADAS de todos].

Samuel: Bueno, la verdad que es muy lindo el programa.

XXXX [hay un comentario de Don Segundo sobre las cualidades de Samuel como músico y maestro comprometido con las familias de la zona].

Samuel: Saludos a los amigos que están ahí en la radio. La situación no me permite, y no puedo asistir al programa por la inundación.

Estas situaciones nos permiten construir el concepto de tumulto lingüístico con visos de que no veremos nuevamente en todo el terreno de nuestra investigación. Ese programa radial que duró 7 años, con varios años intensos de fanatismo manifiesto (con enojos exacerbados de algunos en plena calle del pueblo, porque el programa a veces no se podía realizar), con plena identificación de sus oyentes, con quejas moralistas de otros, con picardías cómplices entre participantes y oyentes, con miles de mensajes de texto enviados en quichua: todo esto daba cuenta de un tipo de intromisión que las buenas 
conciencias puebleras no lo permitían (aunque al final terminaran escuchando el programa como el resto).

Decimos que era un tipo de tumulto lingüístico que casi rozaba lo político (no llegaba a una "insurgencia" ni mucho menos), porque era en ese programa donde algunos participantes decidían pronunciarse en contra del comisionado de ese momento, criticaban las políticas hídricas del gobierno provincial (habida cuenta de las inundaciones de 2010 y 2011), y sobre todo la falta de presupuesto en infraestructura escolar (drama persistente hasta hoy). Había una clave externa para ese ambiente vivido como tumulto: el sector político de Tincho ya había perdido las elecciones de 2008 en su primera presentación, y aguardaban hasta 2013 para hacerlo nuevamente. Corrían murmullos, reuniones, complicidades, y mucha discusión acerca de qué hacer para ganarse más votos. Aunque había una minoría que se identificaba en contra de esta lista de oposición política, el programa permitía un espacio libre donde era permitida la crítica, el disenso hacia la gestión de ese momento. En esos años (de 2010 a 2013) de discusiones políticas in crescendo, el programa radial portaba ese ambiente de joda lingüística. No es cualquier joda, sino la que identifica a un sector masculino de quichuistas que hablan principalmente temas de hombres. Temas donde se "saca el cuero" (critica) al comisionado municipal, se piden temas, se burlan entre sí, se cuentan chistes picantes, piropean a las mujeres presentes, rinden "homenajes" a algunos "patriarcas" (como Sixto Palavecino, Belindo Farías y otros agentes culturales de menor relevancia social). Pero, sobre todo, se ufanan de su masculinidad y declaman incansablemente para "que la quichua no se pierda jamás" (es decir, frecuentemente, pero no es de ningún modo un discurso central en el orden de usos interno de toda la trama radial). Todo eso estaba permitido en esos años del programa.

$\mathrm{Y}$ era lingüístico ese tumulto no solo porque era en quichua (no era un ambiente en castellano "traducido" a dicha lengua) sino que sus participantes habían construido un espacio propio, basado en los parámetros del patio de sus casas. Tincho había logrado darles el espacio y ellos lo tomaron para construir un ámbito lingüístico de hombres (aunque nunca lo dijeran así) donde la irrupción de Shisha era bienvenida, pero más que nada para ser funcional al rol que se esperaba de una mujer de mediana edad: que reaccionara rápido ante las relaciones (piropos rimados) subidos de tono de los hombres que componían el resto del grupo, y para que sirviera como acompañante amena de niños o ancianos en el programa (el rol de "madre"). El ámbito completo de interacciones del programa, fue una de las más visibles manifestaciones de lo que Isabel Requejo (2004) denomina como autorías de la palabra. Sin el tinte de "resistencia" que Requejo otorga al concepto (ella realiza un enorme trabajo de conceptualización después del estallido de 2001, aunque muy atravesado por la expectativa política del momento), el programa radial habilitó formas diversas de autoría lingüística, que para nosotros llegó a un techo y a un límite: el tumulto.

Varios elementos se entremezclaban para lograr el efecto del "patio con frecuencia modulada". Desde esa neutralidad amistosa que representa el chamamé de la zona, el baile de un "gatito" de folklore adentro de la misma radio, los cuentos bien picantes (a veces en quichua y otras veces en castellano) y sobre todo, con fragmentos completos de diálogos en quichua donde la mayoría de las veces nadie traducía nada al castellano, motivada principalmente por esa picardía surgida de la complicidad masculina: ese 
tumulto duró lo que las fuerzas y el tiempo lo permitieron (muchas veces el bolsillo de Tincho que sostenía laboriosamente los almuerzos de esos domingos con los pesos de los auspicios) hasta que el pasaje de "lo cultural" obligó moverse a Tincho, por fuerza de las circunstancias, hacia la efectiva participación política.

\section{6. "Nos hicieron callar"}

Hubo otras actividades contingentes que potenciaron ciertos conflictos. Por ejemplo, con Tincho y un amigo (que es realizador audiovisual) elaboramos un guión completo para presentar en un concurso federal. El fin era realizar un documental exclusivamente sobre todo lo que sucede en el programa radial. Así, viajamos a Llaqta Sur para reunirnos con todos los participantes del programa, porque el proyecto resultó ganador. Ya era 2010, y debajo de enormes chañares éramos más de 25 personas. Mi amigo y Tincho explicaban la propuesta y la buena noticia. Si bien algunos preguntaban con demasiadas sospechas acerca de los fines del documental, al final todos quedaron satisfechos cuando mi amigo les prometió que iba a regalar varias copias del documental para todas las escuelas, cosa que sucedió tiempo después.

El grupo de documentalistas llegó en 2011 para hacer el cortometraje. Con dos cámaras, paneles de iluminación, equipos de sonido, notebooks, se instalaron en una hostería pequeña de un despensero. La idea original (parcialmente modificada por las limitaciones de las tomas y las escenas) fue que el programa en sí estuviera acompañado de muchas otras escenas: la escuela, los patios de las casas, el río Dulce como escenario, un anciano tocando su armónica, niños jugando alrededor de un algarrobo, muchachos saliendo del colegio y caminando por las calles, el paisaje polvoriento y salitroso, etc.

También había tomas donde los principales participantes del programa hablaban a la cámara. El caso de don Segundo, a quien le tocaba hablar solo y directo a la cámara, era de mucha expectativa. Con su rostro moreno y duro de 73 años, fue maestro, director, gestor cultural, terrateniente de su localidad, fiestero, chamuyador, vital. Dirigió muchos años los destinos de Pencayoj, el pueblo que lo vio nacer. Si viviera en Texas, sería un perfecto vaquero que pide un wisky en una taberna, con las piernas visiblemente arqueadas y un andar regio. Pícaro en su habla y duro en sus juicios, no hay personas que logren resistirse a sus palabras traviesas, tanto en quichua como en castellano. Actúa como si fuera un hombre muy enojado, y después te zampa una palabrota que todos festejan. Baila los escondidos y gatos como si fuera un zorro, dándole vueltas a la gallina: así bailaba con Shisha un gato cuando los filmaban para el documental, y así bailaba don Segundo en las "fiestas de trincheras" de febrero, cuando nadie lo filmaba. Su temperamento pareciera ser siempre el equivalente a una tormenta a punto de estallar, pero siempre se queda mostrando una mueca incuestionablemente pícara. De un modo que resulta muy complejo de pasar a palabras, don Segundo reflejaba, de todas mis estadías de campo, el ejemplo más reconocible de un bilingüe atravesado por el agonismo y la picardía, dos aspectos fundamentales (algunas veces divergentes y muchas otras concurrentes) cuyas numerosas aristas vengo exponiendo en esta descripción lenta (Quirós 2011). Según la decisión final de mi amigo (el realizador y su equipo), el discurso filmado de don Segundo quedó ubicado como la parte más "histórica" de la lengua en el documental. 
Y don Segundo se dispuso a hablar a la cámara. Comenzó y siguió hablando completamente en quichua. Larga escena de filmación, durante largos minutos, hablando algo de historia de la lengua, algo de historia de los viejos y olvidados molinos harineros de mediados de siglo XIX, de las inundaciones que se llevaron todas las cosechas de trigo y de algodón. Era demasiado evidente que no solo sus palabras, sino también su "discurso", representaban al arquetipo del "anciano guardián del quichua" (para el documental audiovisual). Quien había sido maestro, un recio director de escuela (con su rostro severísimo y cruzado sus arrugas), cambió esa parte "histórica" que venía desarrollando, y comenzó gradualmente a reflexionar de otro modo ante la cámara. Comenzó a referirse a la tan mentada vergüenza para hablar quichua:

-Gentes ninku "qamkuna ancha callaus kanki". Mana callaus kayku. Mana [la gente dice "ustedes son muy callados". No somos callados. No]

Y de repente cambió al castellano para decir solamente una frase (fue la única frase en castellano de todo su discurso), pero con mucha intensidad hacia la cámara -y para que nos entiendan bien... nos hicieron callar-.

Se refería a "la quichua" y al discurso de prohibición. Y en ese rostro tan inconmovible, sus ojos comenzaron a humedecerse levemente. Dijo unas palabras más para cerrar, y terminó la filmación. Algunos que estaban presentes detrás de la cámara, lloraban. Don Segundo fue abrazado inmediatamente por uno de los muchachos técnicos, y otro le ofreció una servilleta para secarse los ojos. "Gracias waay" [mi hijo], le contestó don Segundo.

Terrible paradoja de quien es bilingüe, que fue maestro, que fue un hombre de actuar "duro" toda su vida, corrigiendo carpetas de niños quichuistas. Siendo maestro, no sabemos si fue Sarmiento o fue Simón Rodríguez. Agreguemos el hecho fundamental de que gran parte de su vida activa tuvo su enorme hacienda de vacas, cabras y caballos (con toda la implicancia de ese rol de clase y de dominación política sobre sus vecinos, en su zona). Pero ahora, frente a la cámara, decidía hablar como un quichuista que quería dar un "mensaje, un legado para nuestros nietos", pero a esa parte clave decidió denunciarla en castellano, como si toda su vida hubiera sido una tristeza. Como si su vida de maestro, a la vez la hubiera sufrido como un niño bilingüe que sufre en la escuela estando con un docente. En ningún momento aparecía esa picardía (en el sentido de autoconfianza, propia de quien ejerce dominio en su zona y se ufana de hablar por los demás). Toda esa risa que generaba con esa actitud de cowboy seguidas de sus muecas de picardía, ahora nos estaba diciendo otra cosa, a partir de ese testimonio frente a un lente de cámara. Terminada la toma, ahora don Segundo lloraba en el patio y se secaba los ojos con otro pañuelo que le había alcanzado una muchacha sonidista del equipo. Nuevamente, don Segundo agradecía el gesto.

Pero había un nuevo problema que gradualmente comenzó a emerger, como veremos en algunos diálogos: los demás comenzaron a cuestionar a Tincho porque -en numerosas ocasiones- don Segundo ya no soltaba el micrófono. Ya habían pasado varios domingos, y don Segundo ya no era solo un invitado más. Decio, Pedro, Rumitu, Pantaleón y Samuel se sentían desplazados. Nótese que Shisha no se sentía perjudicada: el reclamo era más bien era cosa de hombres. Cada intervención del micrófono en don Segundo (y obviamente en los demás varones) era para ver quién decía más cosas en quichua. Nadie 
se le quería quedar atrás: don Segundo los estaba "pordelanteando". Un agonismo quichua, cuyos modos eran sentidos en su máxima intensidad. Si alguna vez hubo algo parecido a la vergüenza frente al micrófono, ya nadie se acordaba: ahora era la disputa por ver cómo quitarle el micrófono, y a la vez no hacerlo enojar porque no querían problemas. Llegados a este momento, agonismo y picardía se funden intensamente, ya sin diferencias.

\section{El patio de cada uno}

El tiempo socialmente necesario para desarrollar la oralidad, estaba roto durante esas ocasiones. Había una propuesta de intercambio (el programa mismo) donde las partes en situación agonística se desafiaban con sus recursos de quichua. Pero para poder hacerlo, debía respetarse ciertos turnos de habla: esto jamás sucedió. No nos referimos a una organización "democrática" de turnos de habla, sino más bien a una lucha amena (un desafío entre pares) para intercambiarse el quichua que cada uno necesitaba decir, y necesitaba hacer saber a los demás. Todo eso estaba roto cuando alguien se adueñaba del micrófono y no lo "soltaba", no lo "pasaba" para los demás: la "demostración" ante los demás se tornaba imposible. No dejaba a los demás desplegar sus propios repertorios: sus bromas, sus comparaciones y burlas, sus propias "salidas graciosas". El programa radial se comportaba como una verdadera economía moral de intercambios. Por eso Decio, después de participar activamente varios meses, terminó postergado y sentado detrás de todos, sin participar. Pasadas varias semanas, decidió no aparecer más en el programa. Una tarde, fuimos con Tincho en su moto a visitarlo. A pesar de las promesas de Tincho, no logró convencerlo de que volviera. Desconozco si don Segundo supo alguna vez el motivo de la salida de Decio.

Doña Norma: Kayp puriyku chawpi chinkasqas, qaachkarayku [aquí andamos medio perdidos, estábamos viendo (por dónde salir de la inundación)]

Segundo: Enteros aguas kaypé. Mayman rechkaranki? [Es todo agua por acá. ¿A dónde estaba yendo?

Norma: Bueno don Piñakilu [don enojadito (broma, en referencia al rostro duro de don Segundo)], Fiestaman Señor de los Peligros chayachkas, yakuan qonakorayku estábamos llegando a la fiesta del Señor de los Peligros, y nos hemos dado con agua (les llegó el agua).

Segundo: Bueno, cha Señor de los Peligros uyarisoq rin [ese Señor de los Peligros te va a escuchar]. Es un santito muy chiquito, muy milagroso, yo lo he conocido, allá en Mal Agua (una localidad).

Norma: ¿En qué voy a ir ahora? Solamente en avión (ironía).

Segundo: Decile a los Contreras de Manca Paso (una localidad cercana), esos son platudos. Esos te van a llevar tirando un avión o un helicóptero. Su niña es muy linda. Se parece al padre. Hablando de niñas, venga usted, la invito a que pase (invita a pasar a la hija de doña Norma)

Tincho: Achka ancha kusikus Normita, presenciaykitá agradeceyké [muy contentos estamos, le agradecemos la presencia]

Hija de Norma: Le escuchamos todos los domingos, gracias

Segundo: Doña Norma es una reliquia que está quedando en Mal Agua. Para mí es como una madre. Ella tenía un negocio y sabía vender mercadería. Y para ahí sabía vender yo. Tus hijos son medios cantores, músicos ¿ah? 
Shisha: Dejuru [seguramente]

Segundo: Dejuru tarporanki chay artistas, Normita kunanlla pallachkanki. ¿Manachu Shisha? [Seguro que has sembrado esos artistas, y ahora nomás estás cosechando Normita ¿no es cierto Shisha?]

Decio: Voy a intervenir, es una señora muy guapa de Mal Agua. Y la conozco desde hace mucho. Vendiendo lo que el campo le ofrecía, ella ha alimentado a sus hijos. Recuerdo cuando yo era chiquito, sabía vender queso, arrope, de todo. Qué lindo, sus hijos son grandes, algunos maestros. Mucho me alegro.

Segundo: Suklla yana ovejitat lloqsipora. Sutin kan "Chanchita", ancha llulla kan qellapas [no sólo le ha salido oveja negra. Se llama "Chanchita", es mentiroso, vago] (se ríe doña Norma)

Rumitu: No, es medio feíto pero muy guapo (RISAS DE TODOS) del todo parecen kuchiyna mikuchisqa akaan [del todo parece chancho alimentado con mierda (CARCAJADAS de 20 segundos de TODOS)]. ¡No! ¡Es broma! es el aprecio que le tenemos hacia él. No, es lindo y es guapo. Rellenito me lo anda ahora Chanchi.

Pantaleón: Cha "Chancha" challuasta mikus wiksat wiñachipora [ese Chancha comiendo pescado le ha hecho crecer la panza].

Segundo: Bueno Doña Dorita, mucho te agradecemos, hasta otro momento, y que Dios los bendiga. A todas las chicas de Mal Agua deles un abrazo, y un beso de mi parte, menos a "Chucuru", ese es personaje de mal agüero [risas] (otra broma).

Norma: Su señora sigue jovencita (en referencia a Chucuru)

Segundo: ¿Cuál de las señoras?

Norma: La principal suya [risas]

Pantaleón: Él sabe (Segundo) porque era maestro antes [RISAS]

Segundo: Upallay hom! Chayaptey brujay maqaaq rin [iCallate hombre! Cuando llegue a casa me va a pegar mi bruja (CARCAJADAS)]

En medio del drama de la inundación, este tipo de bromas eran solo posibles en este programa radial quichua, no en otro. La cargada a "Chancha" porque es "vago"; la cargada a los Contreras de una localidad cercana porque serían "platudos" y porque don Segundo les pide jocosamente un helicóptero para los inundados; el saludo a todos menos a Chucuru (otra broma a un poblador conocido de un paraje); y la broma a que la señora es la "principal" (en referencia machista y burlona a que hay otras mujeres que son propiedad secundaria de ese hombre). Muchas de esas cosas fueron dichas con ritmo veloz, y utilizando recursos del quichua que a otros hablantes les parece quichua pura, o "el mejor quichua sabe decir don Segundo, él sí sabe quichuar bien".

Ofrecemos un marco de comprensión sobre qué significa eso (percibido por ellos con categorías propias) como "pureza", "ligeritu" o "el mejor quichua", con este tramo de charla:

Tincho: Bueno Samu (se dirige a Samuel), cuidakuy, cha piña astaan machaqwaykunarayku kan [cuídense, el peligro es más por las víboras].

Segundo: Amigo, si lo pica a Samuel, se va a morir la víbora (risas).

Samuel: Pensando en los inundados, el otro día le pregunté a la enfermera si tiene los primeros auxilios, y me ha dicho que no, que no hay en ningún lado. ¡Mana imatá kan! mañakoq rin niasa kara [¡no había nada! me había dicho que iba a pedir] Segundo: Noqa yachani machaqway kaniptin imayna ampiyta. Wasiyman riysh ampinasuykishpaq, ampatup chukchaan, palan-palan kichkasninpas, atallpa 
lechinan, chiyap ñotqonan [yo sé cómo curar cuando pica la víbora. Vayan a casa para que los cure, con pelos de sapo, espinas de palan-palan ${ }^{23}$, leche de gallina y ceso de liendre] (CARCAJADAS 20 segundos]

Tincho: ¿Cómo es eso del ceso de la liendre?

Segundo: El ceso de la liendre es medio blanquito, yo tengo medio kilo (carcajadas). Hace mucho he guardado porque antes sabía tener muchísimos piojos, hasta en el cuerpo.

Shisha: Yo no he alcanzado eso, pero sabían decir que en los cuellos de la camisa sabían estar llenos de piojos, ciertochu kan Don Piñakilu? [¿es cierto don Enojadito?] Segundo: Chay mana imapas kan. Unay chiyata gentes mikoranku. Sipaspa waan nipora: "Mama, chiyast choqay ancha yarqayrayku" [Eso no es nada. Antes al piojo se lo comía. La hija de una señora le ha dicho: "Mamá, vamos a expulgarnos porque tengo mucha hambre"] (CARCAJADAS)

Shisha: Cheqa kaq kasa kara, don Segundo [había sabido ser verdad, don Segundo]. Menos mal que habías guardado el ceso de liendre, que puede hacer mucha falta.

Para desentrañar qué es esa "quichua pura", no es útil un análisis meramente lingüístico. La quichua pura es más bien un capital reconocido por los demás: no tiene ninguna relación con el porcentaje de quichua que un hablante avezado desarrolle en su alocución y que eso evidencie "pureza". Se trata de otro aspecto. Es el tipo de repertorios (Gumperz 1982) desplegados por cada participante, que el espacio radial fue habilitando. Lo que aquí se construyó durante siete o ocho años, fue un despliegue exacerbado de recursos: conocimiento del territorio, saberes culinarios, medicina del monte, habilidades de la cría del caballo, saber cazar, utilizar supuestos brebajes y pócimas para obtener amores (o para curar la picadura de una víbora con "pelos de sapo"), la fenomenal demostración de hombrías y comparaciones humorísticas (excesivamente frecuentes y bajo metáforas) con el tamaño del pene, las capacidades amatorias hacia una mujer, y hasta la capacidad social para mantener simultáneamente una o varias situaciones de infidelidad, el piropo y las "relaciones" (en forma de coplas). Pero por sobre todos estos elementos, la clave ideológica es el coraje (Karlovich 2018: 33) desplegado por la presión de las interacciones, lo cual supone el intercambio de ciertas situaciones de desafío (agonísticas) entre hombres. Basado en otros temas narrativos con referencia a la Salamanca, Karlovich postulaba que el coraje operaba verdaderamente como la "clave cultural del santiagueño". Efectivamente acordamos con esa interpretación antropológica, pero estaba faltando una base material para comprender por qué el coraje estaba actuando como un catalizador ideológico en nuestro escenario de estudio.

\section{La base material}

Todos los "recursos" descriptos (imposibles de sistematizar bajo categorías demasiado generales), puestos en la escena radial, conformaban un mega-repertorio quichua, percibido por los demás como "muy lindo le saben hablar la quichua en la radio". Ese "muy lindo" no se compone estrictamente del despliegue propiamente "lingüístico", sino de otros elementos. Es la trama sociolingüística aquí expuesta como descripción

\footnotetext{
${ }^{23}$ Planta medicinal, de textura carnosa y sin espinas.
} 
densa que rodea, atraviesa y reorganiza el repertorio lingüístico de cada participante. Estamos entrando a un terreno moralmente cuestionable (para cierta mirada pública y "respetuosa" hacia esta lengua o hacia las declamaciones folklóricas esencializantes, que son absolutamente dominantes en la mirada "provinciana"). Estamos diciendo que el contenido endógeno quichua está atravesado por estos temas que no son los típicos atribuidos a dicha lengua. Son estos y no otros. No hay otros temas "ocultos" a la espera de ser hallados y valorados como si fueran los sentidos "profundos" de esta lengua. Un remedio pícaro para amoríos, referencias sexuales, burlas a vecinos: ¿habría que enmarcar al quichua solamente en un ya tipificado cuadro subjetivista que ya fue registrado por notables e intelectuales del siglo $\mathrm{XX}$, y que quedó así, registrado como "lengua de patio", "ancestral", "indígena", de "intimidad familiar", o de "abuelas a nietos"? Es muy notorio que estos elementos "subjetivistas" existen y son intensos para el mantenimiento (aún sorprendente) del quichua, pero por sí mismos no explican absolutamente nada acerca de las condiciones efectivas de mantenimiento. Releamos la lista anterior puesta entre comillas: siguen siendo "atributos" bajo los cuales hay una base material. Estaba allí, se proyectaba a cada momento en el programa radial, pero dicha base no era jamás explicitada u objetivada como tal en ningún momento.

Como podría suponerse, no se trata de un mero conocimiento territorial, o de "saberes ancestrales" del monte (es decir, conocimientos "reales" como curar la tos con jarilla, o bajo bromas como acumular "cesos de liendre"), o un conocimiento compartido entre vecinos que intercambian bromas desde la radio hacia sus destinatarios que sufren la inundación. No hay ninguna identidad ancestral, milenarista o indígena desplegada en estas prácticas discursivas socialmente eficaces. Buscamos comprender el factor clave de las bromas que alivianan un poco el drama de las inundaciones o la sequía, las referencias al pene o las burlas casi escandalosas que rompen el hielo en la radio, abren $\mathrm{y}$ potencian ese ámbito de patio bilingüe. $\mathrm{O}$ dicho de otro modo, la clave motora de esa socialización intensa de bilingües que asumen un tipo particular de autoría de la palabra radial (aunque de modos muy específicos y situados que hemos descripto aquí).

Nada de lo descripto fue pensado estratégicamente por Tincho ni fue orquestado racionalmente por sus participantes. La motivación efectiva en estas interacciones sigue posicionada en esa picardía de la masculinidad cómplice (Andreani 2020) que incluye a mujeres de un modo que no es pasivo, sino de una forma singular de amistad "reactiva". Aunque Shisha haya participado muchísimo (y algunas mujeres ancianas con menos frecuencia), ella sabía que su rol era minoritario, pero aun así ella se sentía contenta, expectante, nerviosa por querer participar (lo reactivo). Esa picardía cómplice entre hombres (que a veces se torna muy machista por lo que dicen, aunque ellos jamás lo sepan ni lo reflexionen de ese modo, y jamás fue reflexionado así por los oyentes) activaba una fuerte gravitación no solo de otros muchachos, adultos y ancianos, sino también de mujeres como Shisha, quien actuaba con "humor reactivo" hacia las ofensas sexuales, además de otras mujeres del pueblo y del "campo". Esa picardía (descripta en estos términos) es como un hau (Mauss 2010 [1924]) que enlaza oyentes con participantes, de todas las edades y sexo: es el principio organizador del ambiente que otorgaba eficacia a todo el programa. Por eso algunos se enojaban cuando el programa no se podía realizar porque se cortaba la luz, o cuando Tincho debía viajar a Santiago Capital, o hacer alguna gestión: había una deuda que el tiempo solo la acrecentaba 
(Bourdieu 1977) porque ellos sabían que Tincho debía entregarse a ese programa. Él, a su vez, se sentía atrapado en la responsabilidad (vista como social y cultural, pero para para él también "política") de mantener ese hau sociolingüístico.

Pero ese hau, esa picardía actuada, vivida y sentida por todos, quienes se sentían adentro, en esa estructura de sentir (Williams 1988) propuesta por el programa precisa de una base material. Llegados a este punto, es evidente que el origen social de dicha picardía no estaba en este programa radial, sino que ese ambiente la habilitó y amplificó hasta niveles insospechados (si lo medimos según el imaginario rural de toda la zona). Reformulamos: no viene del programa, sino que se amplificó a partir de este. Viene, entonces, de otro lado, y el programa refractó algo que ya estaba ahí, practicándose durante décadas.

La novedad auditiva-técnica, y la reproducción (potencialmente un tumulto) de temas, interacciones orales propias del patio: una mezcla de dos elementos estaba generando algo nuevo, pero su matriz ideológica era reconocible y identificable por todos. Entonces ¿qué motivaba esa pasión por el programa, esa alegría en estos oyentes? ¿En qué otros ámbitos previos se bromeaba (y especialmente entre quiénes) para curar la picadura de víbora usando "pelos de sapo y sesos de liendre"? Dicho de otro modo: ¿qué tipo de transferencia se estaba realizando eficazmente desde otros ámbitos de uso bilinguies hacia este nuevo espacio, la radio, que operaba como propagadorapotenciadora? ¿Cuáles eran esos "otros" ámbitos de uso con más anclaje material? ¿Cuál era, entonces, la base material de la picardía?

Para desentrañar de dónde viene esa picardía, tuvimos que recorrer un camino que va más allá de este programa radial. Nos animamos a ponerle "nombre" a cierta clave cultural que sostiene a la lengua. O mejor dicho, no es "cultural", sino una clave moral que los discursos identitarios lo representan como ese "tesoro" que supuestamente es resguardado en cualquier lengua nativa, el que da sentido "genuino" a su carácter de lengua "ancestral", "indígena", o "de la tierra", o cualquier otra caracterización nativista $^{24}$. Fuimos más allá de esas ideologías sobre esta lengua, o mejor dicho, describimos un más aquí de los hablantes. No hace falta, entonces, empantanarnos en el romanticismo antropológico para dar cuenta de que no existe ninguna clave cultural "oculta": se trata de ciertos mecanismos sociales que deben ser descriptos y explicados, y que poseen su propia historicidad.

Expliquemos, ahora sí, algo fundamental que no fue dicho en todo el trabajo. Tincho, Decio, Guri, don Mansi, don Anush, el maestro Digush, Pedro, Guillote, el Rengo, inclusive el marido de Shisha, los escasos músicos de folklore, los numerosos músicos de chamamé que se disputaban un lugar para tocar los domingos, y hasta los muchachos "mirones" que husmeaban alrededor de la radio: todos son trabajadores "golondrina". Algunos como don Anush, ya tenían más de 60 años trabajando bajo diferentes modalidades de explotación (algodón, caña de azúcar, y principalmente obrajes forestales) y otros como Pedro y Tincho que desde hace 15 o 20 años años viajan para el despanojado de maíz para semilleras multinacionales como Syngenta o Monsanto. La

\footnotetext{
${ }^{24}$ En otras palabras, la supuesta cifra o secreto que Murdock aprende del chamán indígena, en el cuento "El etnógrafo" de Jorge Luis Borges, y ante lo cual dicho personaje "sacrifica" su futuro académico porque decide no difundirlo ni publicarlo ante nadie.
} 
trama de usos e ideologías sobre el quichua tiene una de sus motivaciones fundamentales en esa picardía (Andreani 2014) pero que está situada en el intenso e histórico ámbito del trabajo rural migrante estacional (Neiman 2009; Tasso y Zurita 2011; Desalvo 2013) el cual se estructura como un espacio de intensa socialización bilingüe (Andreani 2013-2016-2020). El proceso mismo del trabajo "golondrina", o mejor dicho, su efectiva materialidad como proceso de explotación, es la fuerza motriz de la socialización bilingüe de sus integrantes (obreros). Ese es el verdadero "empuje", cuyo impacto y cuya fuerza social es la que estructura las acciones, posiciones ideológicas y el juego de la interacción que se visibiliza (o mejor dicho, se hace audible) en los participantes el programa radial (sean hombres o mujeres, sean jóvenes o ancianos) que hemos descripto y analizado.

La respuesta, entonces, se sostiene en relaciones sociales reales, en este caso, de explotación laboral: los 35.000 y hasta 50.000 obreros rurales migrantes que despanojan maíz, cosechan papa o cortan girasol en la Pampa Húmeda, quienes siguen produciendo, desde afuera y durante todo el siglo XX hasta la actualidad, todo un sostén material que generó innumerables narrativas, anécdotas, burlas, chistes sexuales, sobre otros y sobre sí mismos. Y antes, los 60.000 obreros que entre las décadas del 40 hasta los 70 viajaban al algodón chaqueño y la caña tucumana. Y poco antes, los 100.000 obreros forestales en los obrajes del Chaco santiagueño, los cuales conformaban más de la mitad de la población activa total (PEA) a comienzos del siglo XX en la provincia.

Este planteo se sitúa muy por fuera de las frecuentes miradas culturalistas de los notables e intelectuales provincianos, atiborrados en declamaciones sobre la "ancestralidad" del quichua. Incluso un "patriarca" local como don Segundo, quien ejerció como burgués ganadero en su zona y no como obrero golondrina, era a su vez uno de los que "mejor habla quichua", no solo por su propia socialización familiar, sino también por el intenso contacto con sus obreros rurales (vecinos) durante décadas. Esa relación de explotación se basaba en una trama social de muy baja densidad, acorde a la escasa productividad del capital de don Segundo (y la consecuente ausencia de tecnificación del proceso de trabajo). Por eso "la quichua" era tan intensa, sea en la explotación con el patrón (don Segundo) como en la relación horizontal entre explotados (obreros golondrina).

Picardía, agonismo, "ganas", participación, gestión cultural y capitalización política: categorías que no se explican por sí solas, sino que debíamos hallar su sostén en otros procesos reales, influyentes y objetivos. Relaciones sociales de explotación que originan, mantienen y consolidan a la sobrepoblación relativa rural santiagueña. Necesitábamos explicitar el despliegue vivo de esas categorías y prácticas, desde nuestra relación construida socialmente en el campo, pero mucho más desde una perspectiva que no ocultara la dimensión material. Esa base material, que nunca se despliega en toda su fuerza a simple vista, era la que sostenía y potenciaba la eficacia social de un programa radial bilingüe.

Toda esta descripción es el aporte que hacemos, desde un lugar muy diferente, para pensar no solamente la discusión sobre las políticas lingüísticas, sino también otra perspectiva más realista sobre el mantenimiento social de lenguas muy minorizadas como esta variedad austral de la familia general quechua. 


\section{Bibliografía}

Albarracín, L.; Alderetes, J.; Pappalardo, M. T. (2001). "Comunicación y Exclusión: el caso de las comunidades bilingües minoritarias". II Jornadas de Periodismo y Comunicación, 15 y 16 de Noviembre de 2001, Facultad de Ciencias Humanas de la Universidad Nacional de La Pampa.

Albarracín, L. I. (2011). La quichua. Ejercicios y gramática. Volumen II. Buenos Aires: Dunken.

Albarracín, L. I. (2016). La quichua. Ejercicios y gramática. Volumen III. Buenos Aires: Dunken.

Alderetes, J. (2001). El quichua de Santiago del Estero. Gramática y vocabulario. San Miguel de Tucumán: UNT.

Albarracín L. I. y Alderetes, J. R. (2001). "La problemática de una comunidad bilingüe en nuestro país". Actas del Primer Congreso sobre Problemáticas Sociales Contemporáneas, Facultad de Humanidades y Ciencias, Universidad Nacional de Santa Fe. ISBN 987-508-163-9.

Albarracín L. I. y Alderetes, J. R. (2004). "El Quechua en Argentina. El caso de Santiago del Estero". International Journal of the Sociology of Language, Vol. 2004 (167).

Alén Lascano, L. (1992). Historia de Santiago del Estero. Buenos Aires: Plus Ultra. Andreani, H. (2013). "Migración, maíz y silencio. Notas sobre el bilingüismo (quichua-español) de los trabajadores 'golondrina' santiagueños". Gazeta de Antropología, 29 (1), 2.

Andreani, H. (2014). Quichuas, picardías y zorros. Conflictos y tácticas en una comunidad bilingüe. Santiago del Estero: EDUNSE.

Andreani, H. (2016). "Akush kichwaq guasapi yanasus. Repertorios bilingües quichua-castellano en redes virtuales de obreros migrantes santiagueños". En: Revista del Museo de Antropología (UNC), 13 (2): 161-174.

Bravo, D. (1956). El quichua santiagueño. Reducto idiomático argentino. San Miguel de Tucumán: UNT

Brighton, H. (2003). Simplicity as a driving force in linguistic evolution. Tesis de doctorado en lingüística. Universidad de Edimburgo.

Carol, M. (1943). La gran sequía. Santiago del Estero: Líneas de tiempo

Carrizo, J. (2014). Juan Felipe Ibarra y los Taboada: Caudillos y Políticas Fiscales, Económicas y Sociales. Santiago del Estero: Idearte.

Chang, L. (2020). "Algunos aspectos históricos, económicos y geopolíticos en la conformación del español andino y del quichua santiagueño en la región Noroeste de la Argentina durante la colonia". Revista de la Sociedad Argentina de Estudios Lingüísticos, colección 2020, № 2, pp. 7-32.

Cebrián Herreros, M. (2001). La radio en la convergencia multimedia. Barcelona: Gedisa

Dargoltz, R. (2003). Hacha y quebracho. Historia ecológica y social de Santiago del Estero. Santiago del Estero: Marcos Vizoso Ediciones.

Das, V. y Poole, D. (2008). "El estado y sus márgenes. Etnografías comparadas". Cuadernos de Antropología Social (27), pp. 19-52 
Desalvo, A. (2013). ¿Campesinos u obreros? Un estudio actual sobre la llamada población campesina de Santiago del Estero (2009-2012). Tesis doctoral en sociología. Universidad de Buenos Aires. Inédita.

Di Lullo, O. (1937). El bosque sin leyenda. Santiago del Estero: el autor.

Duranti, A. (2000). Antropología lingüística. Madrid: Cambridge University Press.

Flores, J. (2018). El origen. Explotación y acumulación capitalista en el Río de la Plata colonial. Buenos Aires: CEICS.

Togo, J.; Garay, L.; Bonetti, C. (2008). "La lengua quichua en Santiago del Estero. Políticas públicas y exclusión”. Indoamérica, Año II, Nº 2, pp. 115-124.

Gandulfo, C. (2007). Entiendo pero no hablo. El guaraní acorrentinado en una escuela rural. Usos y significaciones. Buenos Aires: Antropofagia,

García Dávila, D.; Finol, J. E. (2003). "Teoría crítica, radio e identidad regional: contribución a un análisis teórico". Revista de Ciencias Humanas y Sociales, Vol.19, № 42.

Grosso, J. L. (2008). Indios muertos, negros invisibles. Hegemonía, identidad y añoranza. Córdoba: Encuentro Grupo Editor.

Grosso, J. L. (2018). En otras lenguas. Semiopraxis popular-interculturalposcolonial como práctica crítica. Azogues: UNAE.

Gumperz J.; Hymes, D. (comps.). 1972. Direction in Sociolingüistics. Ethnography of communication, pp. 35-71. Nueva York: Holt, Rinehart and Winston.

Gumperz, J. (1982). Discourse Strategies. Cambridge: Cambridge University Press. Heggarty, P., Beresford-Jones, D. (2010). Archaelogy, Language and the Andean Past: Principles, Methods, and the New State of Art. Boletín de Arqueología PUCP, $\mathrm{N}^{\mathrm{o}} 14$, pp. 29-60.

Hymes, D. (2002) [1972]. "Modelos de la interacción entre lenguaje y vida social”. Golluscio, L. (Comp.). Etnografía del habla. Textos Fundacionales. Buenos Aires: Eudeba.

Farberman, J. (1998). "El peso de la continuidad. Tierra, trabajo familiar y migraciones en Santiago del Estero. Un estado de la cuestión". Población y Sociedad, octubre No 5, pp. 165-186.

Farberman, J. (2019). "Los avatares de la mancomunión. Propiedad indivisa, armonías y conflictos en las costas del río Dulce. Santiago del Estero, siglos XVIII y XIX”. Revista de Indias, N² 275 (4), pp. 111-142.

Karlovich, A. (2006). "De la oralidad a la escritura". Tebes, M. C.; Karlovich, A. Sisa Pallana: antología de textos quichuas santiagueñosk. Buenos Aires: Eudeba.

Karlovich, A. (2018). «Introducción: Supay y Salamanca en Santiago del Estero ». Sosa, J. A. Pallaspa chinkas richkaqta (Juntando lo que perdiéndose va) (pp. 2136). Santiago del Estero: Subsecretaría de Cultura de la Provincia.

Labov, W. (2002). "Driving forces in linguistic change". International Conference of Korean Linguistics. Seoul National University.

Landsman, M. E. (2000). "La lengua en la dominación política (Del Quichua de Santiago del Estero)". VI Congreso Internacional de la lengua Quechua. Santiago del Estero, Argentina. 18 al 14 de octubre.

Ludi, G. y Py, B. (2009). "To be or not to be ... a plurilingual speaker". International Journal of Multilingualism, 6(2): 154-167. 
Martínez, A. T. (2013). Cultura, sociedad y poder en Argentina. La modernización periférica de Santiago del Estero. Santiago del Estero: Edunse.

Mauss, M. (2010). [1924]. Ensayo sobre el don. Madrid: Katz Editores.

Mondada, L. (2004) "Ways of 'Doing Being Plurilingual in International Work Meetings". Gardner R.; Wagner, J. (eds.), Second Language Conversations. Londres: Continuum.

Muñoz; J. J. (1997). La Radio. Teoría y Práctica. Madrid: RTVE

Neiman, G. (2009). "Estudio exploratorio y propuesta metodológica sobre trabajadores agrarios temporarios". Con la colaboración de Marcelo Bachur (MTESS) y Andrés Resa (RENATRE) Ministerio de Economía y Producción, Secretaría de Agricultura Ganadería, Pesca y Alimentos. Proyecto de Desarrollo de Pequeños Productores Agropecuarios (PROINDER) Buenos Aires.

Nussbaum, L. (2012). "De las lenguas en contacto al habla plurilingüe". Unamuno, V.; Maldonado, A.: Prácticas y repertorios plurilingües en Argentina. Barcelona: GREIP.

Quenel, C. (2014) [1980]. Narrativa completa. Villa María: EDUVIM.

Quirós, J. (2011). El porqué de los que van. Peronistas y piqueteros en el Gran Buenos Aires: una antropología de la política vivida. Buenos Aires: Antropofagia.

Quirós, J. (2014). "Etnografiar mundos vívidos: desafíos de trabajo de campo, escritura y enseñanza en antropología". Revista Publicar, Año 12, N. 17: 47-65.

Requejo, M. I. (2004). Lingüística Social y autorías de las Palabra y el Pensamiento: Temas de debate en psicología social y educación. Buenos Aires: Cinco.

Scalabrini Ortiz, R. (1940). Historia de los ferrocarriles argentinos. Buenos Aires: Plus Ultra.

Schieffelin, B. y Ochs, E. (1986) “Language socialization”. Annual Review of Anthropology, 15: 163-191.

Sosa, J. A. (2018). Pallaspa chinkas richkaqta (Juntando lo que perdiéndose va). Santiago del Estero: Subsecretaría de Cultura de la Provincia.

Stark, L. R. (1985). "Historia del Quichua de Santiago del Estero", en H. M. Klein y L. R. Stark (eds.) South American Indian Languages: Retrospect and Prospect. Austin (Texas): Universidad de Texas.

Tasso, A. (2007). Ferrocarril, quebracho y alfalfa. Un ciclo de economía capitalista en Santiago del estero. 1870-1940. Buenos Aires: Alción.

Tasso, A. (2011). "La sequía de 1937 en Santiago del Estero. Antecedentes y consecuencias de un acontecimiento ambiental". Trabajo y sociedad, $\mathrm{N}^{\circ} 17$, Vol. 15, pp. 17-39.

Tusón Valls, A. (2002). "En análisis de la conversación: entre la estructura y el sentido. Estudios de sociolingüística, 3(1), pp. 133-153

Unamuno, V. (2011). "Entre iguales: notas sobre la socialización lingüística del alumnado inmigrado en Barcelona”. Sociolinguistic Studies, 5(2): 321-346.

Voloshinov, V. N. (1992) [1929]. El marxismo y la filosofía del lenguaje. Los principales problemas del método sociológico en la ciencia del lenguaje. Madrid: Alianza Editorial.

Williams, R. (1997) [1977]. Marxismo y Literatura. Barcelona: Península. 
Wittig, F. G. (2009). "Desplazamiento y vigencia del mapundungún en Chile: Un análisis desde el discurso reflexivo de los hablantes urbanos". Revista de Lingüística Teórica y Aplicada, 47 (2), II Sem, pp. 135-155.

Documentos audiovisuales

Gerez, Daniel (2012). Salavinamanta tukuypaq. Documental, 26 minutos. Ganador del Concurso Federal "Nosotros" (INCAA). 